\title{
Die Mimesis des Heros: Pagane Helden in christlicher Deutung
}

Tò yà

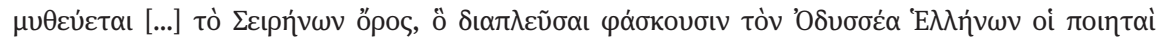

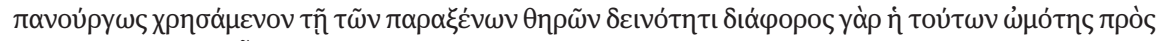

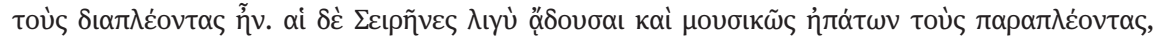

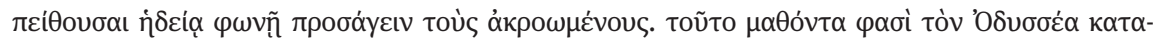

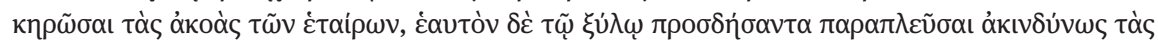

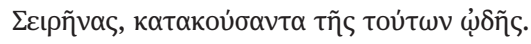

Denn ein solches Meer ist voll wilder Tiere und unpassierbar, wie zum Beispiel das sizilische, von dem die Sage geht, daß der [...] Sirenenberg sich dort finde; Odysseus hat es nach den griechischen Dichtern durchsegelt, indem er die grausamen, bösen Bestien gar schlau behandelte; die Sirenen waren nämlich von ausnehmender Wildheit gegen die Vorüberfahrenden. Sie pflegten aber gar süß und lieblich zu singen, täuschten so die Vorübersegelnden und verlockten sie durch ihre liebliche Stimme, heranzufahren. Da er dies inne geworden, verstopfte Odysseus seinen Gefährten die Ohren mit Wachs; er selbst aber ließ sich an den Mast binden, fuhr so ungefährdet an den Sirenen vorbei und hörte ihren Gesang. ${ }^{1}$

Die Sirenen, die im paganen Mythos sowohl Weisheit als auch die Erfüllung aller Träume versprachen und eine positive wie negative Konnotation innehatten, werden von den Christen in einer diese Ambivalenz zusammenführenden Deutung zu einem verführerischen Lockmittel, das den Gläubigen vom rechten Pfad abbringen will und gerade in der paganen Bildung bestehen mag, besonders, wenn es etwa im „(pseudo)christlichen Gewand der Häresie daherkam“.²

1 Hippol., Ref. omn. haer. 7,13,1f.; H. Rahner, Griechische Mythen in christlicher Deutung, mit 11 Abb. und einem Geleit- und Schlüsselwort v. A. Rosenberg, 4. Aufl., Basel 1984, S. 308f. Ders., Symbole der Kirche. Die Ekklesiologie der Väter, Salzburg 1964. Übersetzung nach: Des heiligen Hippolytus von Rom Widerlegung aller Häresien, aus dem Griech. übers. v. K. Preysing (BKV, 1. Reihe, Bd. 40), München 1922, S. 194.

2 Vgl. Oehl, der besonders die polemische Auseinandersetzung der Kirchenväter mit der Häresie in den Fokus seiner Untersuchung stellt: B. Oehl, Mythos und Häresie, in: R. v. Haehling (Hrsg.), Griechische Mythologie und frühes Christentum, Darmstadt 2005, S. 311-338; hier S. 333-338, Zitat S. 317. Clemens von Alexandrien verwendet das Verhalten des Helden Odysseus, der an den Sirenen vorbeisegelt, überraschenderweise als Negativfolie. Vgl. dazu C. Markschies, Odysseus und Orpheus - christlich gelesen, in: R. v. Haehling (Hrsg.), Griechische Mythologie und frühes Christentum, Darmstadt 2005, S. 227-253, hier S. 235. Die Sirenen stehen bei Clemens, vermutlich in der christlichen Interpretation seiner Umwelt, für die Wissenschaften, die er wiederum verteidigt (Clem. Alex., Strom. VI,89,1): „Es ist, so formuliert er [Clemens] dagegen, gut und recht, vom Weg der Unbildung abzukommen und sich durch die besonderen Sirenen der griechischen Wissenschaft vom Wege locken zu lassen. "Markschies, S. 235. Darin sieht Markschies eine „energische Mythenkorrektur“, wenngleich Clemens seine Forderung an anderer Stelle wieder einschränkt und damit auch seine neue christliche Lesart des Mythos (Clem. Alex., Protr. XII,118,1). Vgl. Markschies, S. $235 \mathrm{ff}$. 
Es ist Hippolyt, der Kirchenvater, der auf das mythische Bild des an den Mastbaum seines eigenen Schiffs gefesselten Odysseus zurückgreift. Was er hier unternimmt, ist Homerexegese. Wie er haben noch zahlreiche andere Kirchenväter seit der Mitte des zweiten Jahrhunderts Homer verwendet. Der pagane Mythos dient ihnen dabei einerseits als populärer Referenzpunkt, um Argumentationen Gewicht zu verleihen und die christliche Botschaft durch Nachahmung und Umdeutung eines bekannten epischen Bildes zu vermitteln, und andererseits als Negativfolie und Gegenbild, von dem sich ihre christliche Botschaft gezielt unterscheidet. In jedem Fall gemeinsam ist ihnen die Gewissheit der allgegenwärtigen Vertrautheit mit dem homerischen Epos. ${ }^{3}$ Markschies kommentiert das nicht nur von Hippolyt, sondern ebenso von Clemens von Alexandrien aufgegriffene Bild des an den Mast gefesselten Odysseus mit folgenden Worten:

\begin{abstract}
Wenn aber dieser Mast zugleich das Kreuz Christi bedeutet und mit dem Kreuz Christi nach Clemens die Befreiung von den Lastern und schlechten Leidenschaften, also eben von der Macht der Gewohnheit, geschenkt wird, dann kann man [sich] den an den Mastbaum gefesselten Odysseus tatsächlich als Urbild der Kreuzesnachfolge jedes Christen vorstellen. Man kann vermutlich gar nicht überschätzen, welche Bedeutung für die Verbreitung des Christentums in der antiken Welt solche Umkonditionierungen der durch den Schulunterricht allgemein verbreiteten homerischen Szenen hatten [...]. ${ }^{4}$
\end{abstract}

So wie für den Intellektuellen Tertullian alles, was in den christlichen Schriften steht, auch geschehen und wahr ist, gilt dies parallel auch für die Homergläubigkeit seit hellenistischer Zeit. Der Bekanntheitsgrad des Epos seitdem ist enorm, nicht nur wegen der vielen Übersetzungen, sondern auch weil dekorative Bilder auf Ölkannen, Wasserkrügen und Weinschalen alltäglich die Szenen aus dem Mythos nacherzählen, die homerischen Epen die Grundlage jeder Bildung waren. ${ }^{5}$ Die Begeisterung für Homer erfasste auch die Kirchenväter, nicht alle, aber doch viele, denn es gibt kaum einen, der ihn nicht zitiert und christlich interpretiert oder zumindest vehement gegen ihn polemisiert hat. Unweigerlich stellt sich daher die Frage, inwieweit die paganen Vorbilder den christlichen Autoren bewusst oder unbewusst bei der Ausgestaltung der neuen Heilslehre dienten.

3 Dazu Oehl (s. Anm. 2), S. 338: „Der verstärkte Gebrauch mythischer Bilder in der antihäretischen Polemik steht nicht im Widerspruch zu der ablehnenden Haltung der Christen gegenüber dem paganen Mythos im allgemeinen und dessen tatsächlicher oder vorgeblicher Übernahme durch häretischgnostische Gruppen im besonderen. Es war legitim, hier Feuer mit Feuer zu bekämpfen. Denn der Mythos ist Instrument der Polemik und Reservoir allgemein verständlicher Metaphern und leistet so einen Dienst für die rhetorische Ausformung des antihäretischen Schrifttums.“

4 Clem. Alex., Protr. XII,118,1-4 (GCS Clemens Alexandrinus I,83,8-30); Markschies (s. Anm. 2), S. 237.

5 C. Schneider, Geistesgeschichte des antiken Christentums, 2 Bde., München 1954. Vgl. hier Bd. 1, S. 319. Markschies (s. Anm. 2), S. 237. K. O. Sandnes, Imitatio Homeri? An Appraisal of Dennis R. MacDonald's „Mimesis Criticism“, in: Journal of Biblical Literature 124 (2005), S. 715-732, hier S. $716 \mathrm{f}$. 
Bereits Erich Auerbach hat das Prinzip der Mimesis in der Literaturgeschichte untersucht und insbesondere in den Schriften des Neuen Testaments und der Kirchenväter das Prinzip der figuralen Deutung nachgewiesen. Wenn sich auch seine Ausführungen zu den frühchristlichen Schriften und seine Vergleiche mit der paganen Literatur auf bestimmte Beispiele konzentrieren, so bieten sich seine Betrachtungen doch als Ausgangspunkt einer Untersuchung an, die der Frage nachgeht, ob und inwieweit bekannte Bilder der paganen Mythen von christlicher Seite nachgeahmt und nutzbar gemacht wurden bzw. ob heidnische Heroen gleichsam als Präfiguration christlicher Helden zu lesen sind.

Ich möchte Auerbachs Thesen kurz darstellen, um dann an weiteren Beispielen zu zeigen, inwieweit in die frühchristliche Literatur die Figuren des Epos als Deutungsmuster eingeflossen sind.

\section{Auerbachs Mimesis-Gedanke in antiken Kontexten}

„Mimesis“ ist ein griechisches Wort, das im aristotelischen Sinne „Nachahmung“ bedeutet. ${ }^{6}$ Mit der erzählenden Nachahmung hat Auerbach sich in Mimesis z. B. in seinem bekannten Fortunata-Kapitel oder auch im Kapitel über Ammianus Marcellinus Verhaftung des Petrus Valvomeres beschäftigt. ${ }^{7}$ Dabei bezieht er die christliche Literatur mit ein und kommt zu einer ganz eigenen, neuen Bewertung dieser Gattungen. Ausgangspunkt meiner Überlegungen ist zunächst ein älterer Aufsatz Auerbachs aus dem Jahr 1938 mit dem Titel Figura, da er sich dort in einem breiten literaturwissenschaftlichen Abriss mit dem Phänomen der Gestaltnachahmung befasst hat. ${ }^{8}$ Der Figura-Aufsatz stellt eine analytische Abhandlung über die Bedeutung des Figura-Begriffs in der heidnischen und christlichen Literatur dar, unter besonderer Berücksichtigung der kontextuellen Hermeneutik der mit dem Wort verbundenen Vorstellungen, die dann später von Auerbach z. B. im VII. Kapitel von Mimesis über Adam und Eva wieder aufgegriffen werden. ${ }^{9}$

Im platonisch-aristotelischen Sprachgebrauch stoßen wir auf zahlreiche Worte für

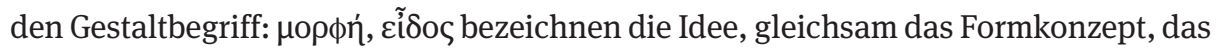
die Materie „informiert“; $\sigma x \tilde{\eta} \mu \alpha$ ist die sinnlich wahrnehmbare Gestalt dieser Form, so Auerbach. ${ }^{10}$ Diese Begriffsweisen fließen in das ein, was die Römer dann unter figura

6 In der Poetik ist genauer Mimesis als die „nachahmende Darstellung einer Handlung“ definiert. Ich habe die zweite verbesserte und erweiterte Auflage von Mimesis aus dem Francke Verlag, Bern 1959, benutzt. Die erste Auflage stammt aus dem Jahr 1946. E. Auerbach, Mimesis. Dargestellte Wirklichkeit in der abendländischen Literatur, 2. Aufl., Bern 1959.

7 Auerbach (s. Anm. 6), Kap. II, S. $28 \mathrm{ff}$., Kap. III, S. $58 \mathrm{ff}$.

8 E. Auerbach, Figura, in: Archivum Romanicum 22 (1938), S. 436-489.

9 Auerbach (s. Anm. 6), Kap. VII, S. $139 \mathrm{ff}$.

10 Auerbach (s. Anm. 8), S. 438. 
verstehen: plastisches Gebilde wie bei Terenz (Eun. 317) - darin schwingt das Verhältnis von Urbild und Abbild mit, des Gestaltwandels und Traum- oder Trugbildes. ${ }^{11}$

Mit der Rezeption paganer Bildungsinhalte bleibt die christliche Apologetik von solchen Überlegungen nicht unbeeinflusst. Es entwickelt sich ein Diskurs darüber, wofür der Name Christus-Jesus steht. Bekanntermaßen ist der Christusname die griechische Version des hebräisch-aramäischen Messias bzw. Meschiah und meint der Gesalbte. Daran sind zahlreiche Vorstellungen geknüpft. So ist der Gesalbte etwa ein König und Erlöser in der Drangsal, einer durch Verfolgung und Fremdherrschaft gekennzeichneten Endzeit. Gerade dieses Beispiel setzt Bezüge zur alttestamentlichen Realprophetie. So sei die Namensgebung Josua-Jesus (Gott ist Hilfe/Heil Rettung) „eine Realprophetie oder vorausdeutende Gestalt des Zukünftigen“ ${ }^{12}$ Dabei wird implizit eine weitere Analogie deutlich. So wie erst Josua und nicht Moses das Gottesvolk in das gelobte Land führte, sei erst das „zweite Volk“ der Christen heilsfähig und steuere auf die ewige Seligkeit zu, weil es auf Jesu Gnade und nicht auf das Gesetz setze. Ein weiteres Beispiel ist das apodiktisch mitgeteilte Abrahamsopfer: „Nimm Isaak, deinen einzigen Sohn, den du lieb hast, und gehe hin in das Land Morija und opfere ihn daselbst zum Brandopfer auf einem Berge, den ich dir sagen werde. “13 Die Opferung Isaaks kann zum einen als Präfiguration des Sohnesopfers, das sich in der Passion erfüllt, verstanden werden. Zum anderen ist es im Sinne Auerbachs von exemplarischer Bedeutung für den gravierenden Stilunterschied zwischen zwei epischen antiken Texten: dem homerischen Epos und der biblischen Erzählung. ${ }^{14}$

Trotz aller Stilgegensätze erscheinen mimetisch bestimmte erzählerische Bilder wie etwa die Narbe als Merkmal einer Verwundung und individuelles Erkennungszeichen unabhängig von der stilistischen Eigentümlichkeit bei Homer einerseits und in der biblischen Erzählung andererseits. Der totgeglaubte Odysseus wird in der homerischen Narbenerzählung aus der Perspektive der alten Amme wieder lebendig, als diese die Narbe betastet. ${ }^{15}$ Das Motiv der Narbe als Erinnerung an die heroische Tat ist Bestandteil des einfachen Glaubens im Heroenkult, wie er auch in den sophistischen Dialog Eingang gefunden hat, so beim Heroicus Philostrats, den in diesem Zusam-

11 Belegstellen bei Auerbach (s. Anm. 8), S. 440 - 49: Lucrez, Cicero, Catull, Vergil, Statius, Virtuv, Plinius Ä. bis Quintilian. Vor allem Quintilian bietet interessante Anknüpfungspunkte in seiner Darstellung des rhetorischen Figurenbegriffs, der schließlich Tropen mit einschließt (Inst. 8 u. 9); siehe Metonymie und Metapher etc., S. $447 \mathrm{ff}$.

12 Auerbach (s. Anm. 8), S. 451.

13 Gen 22,2.

14 Die Adjektive und Abschweifungen der homerischen Gedichte verhindern, so Auerbach, die einseitige Konzentration des Lesers und Hörers auf die aktuelle Krisensituation; „sie verhindern, selbst im schrecklichsten Ereignis, das Aufkommen einer drückenden Spannung. Hier aber beim Abrahamsopfer, ist die drückende Spannung da.“ Auerbach (s. Anm. 6), S. 13, siehe auch S. 9-14.

15 Hom., Od. 19,350 - 505. 
menhang Betz analysiert. ${ }^{16}$ Der tote Heros erscheint leibhaftig in einem gereinigten Körper, der die Narben der heroischen Taten noch zeigt, die Wunden dagegen sind transformiert. Die Narbe des Heros als narratives Grundmotiv, das die Funktion eines identifizierenden Leidensmerkmals hat, kennen wir gleichfalls von den Wundmalen Christi. Furcht und Zweifel an der leiblichen Gegenwart des Heros oder eben Christus werden durch das Erkennen und vor allem das Betasten überwunden. ${ }^{17}$

Interessanterweise greift die frühchristliche Literatur die Motivparallelen heroischer Epiphanien nur sehr indirekt auf, sie konzentriert sich zumeist auf die Deutung der Passion und der Auferstehung im Kontext des Alten Testaments, wobei sich Auerbachs literaturhistorische Betrachtungsweise auf eine „Reihe von Figuren, das heißt Vorverkündigungen und Vorandeutungen des Erscheinens Jesu und der damit zusammenhängenden Ereignisse“ im Alten Testament fokussiert. ${ }^{18}$ Dabei wird deutlich, dass Auerbach die figurale Deutung zumeist, wenn auch nicht ausschließlich, auf die literarischen Verbindungen zwischen Altem und Neuem Testament bezieht. ${ }^{19}$

\section{Figuration bei Tertullian}

In den Schriften Tertullians erkennt Auerbach ein hervorragendes Beispiel der figuralen Deutung. So schreibt der Apologet in Adversus Marcionem, Josua, dessen Name erst bei Hieronymus von dem Jesu unterschieden werden sollte, verkörpere erstmalig eine Figur, die auf Jesus verweise. Hanc prius dicimus figuram futurorum fuisse („Erstmals offenbart sich uns die Gestalt, die auf Zukünftiges verweist“). ${ }^{20}$

Dabei ist die Gestalt des leidenden Gerechten besonders hervorzuheben, denn es geht um die Figuration des Leidens, die Gestaltwerdung des Leidenden durch den Josua-Jesus-Konnex. Das Mysterium des Heils war nach diesem Konzept zur Zeit des Josua noch verborgen, doch in seinem Namen bereits angekündigt. Also ist die prophetische Figur als Hinweis auf Christus gemeint, wobei die Genannten als reale Figuren gelebt haben. Das ist nicht ganz unwichtig, denn Tertullian will keineswegs alttestamentliche Heroen marginalisieren, sondern vielmehr diese als „Vorausdeuter“ vereinnahmen. So wird parallel Adam als Figura Christi und Eva als Figura Ecclesia in der Schrift De anima ${ }^{21}$ entwickelt - wobei im Zusammenhang mit dem Schlaf Adams

16 H.-D. Betz, Heroenverehrung und Christusglaube. Religionsgeschichtliche Betrachtungen zu Philostrats Heroicus, in: ders., Gesammelte Aufsätze IV. Antike und Christentum, Tübingen 1998, S. 128 151, hier S. $130-140$.

17 So etwa durch Jesu Erscheinen vor den Jüngern in Jerusalem (Lk 24,36 - 43; Joh 20,19 - 23) oder als er dem ungläubigen Thomas erscheint, der die Wundmale berühren darf (Joh 20,24-29). In der Version von Lukas teilt Jesus mit den Jüngern außerdem das Mahl (Lk 24, 36-43).

18 Auerbach (s. Anm. 6), S. 51.

19 Auerbach (s. Anm. 6), S. 51f. Siehe auch S. 75.

20 Tert., Adv. Marc. 3,16, mit Bezug zu Num 13,16. Übersetzung H. M. Zilling.

21 Tert., Anim. 43. Vgl. Monog. 5, siehe Auerbach (s. Anm. 8), S. 451. 
die kritische Auseinandersetzung mit philosophischen Positionen steht, waren diese doch nach Tertullian der irrigen Ansicht, Schlaf sei etwas „Außernatürliches“:

Si enim Adam de Christo figuram dabat, somnus Adae mors erat Christi dormituri in mortem, ut de iniuria perinde lateris eius vera mater viventium figuraretur ecclesia.

Denn wenn Adam als Vorbild Christi diente, so bedeutet der Schlaf Adams den Tod Christi, der im Tode entschlafen sollte. Durch den Verlust in seiner Seite [sc. durch die Entnahme der Rippe für die Schaffung Evas] sollte die wahre Mutter der Lebendigen, die Kirche, vorgebildet werden... ${ }^{22}$

„nämlich durch Blut und Wasser, Abendmahl und Taufe“, so Auerbach. ${ }^{23}$ Dazu weiter Auerbach: „Die Art der Interpretation zielte darauf ab, die im AT auftretenden Personen und Ereignisse als Figuren oder Realprophetien der Heilsgeschichte des Neuen zu deuten." ${ }^{24}$

In Adversus Marcionem $(4,40)$ benutzt Tertullian den Ausdruck figuram implere (Vorausdeutung, die Gestalt erfüllen) und parallel dazu auch in der Schrift De fuga in persecutione $^{25}$ im Sinne von confirmare (Bestätigung, Erfüllung, aber auch Ankündigung). Damit meint er die Erfüllung der Schrift in Christus. Christus ist die historische Erfüllung und Bestätigung der auf ihn hindeutenden Realprophetien. ${ }^{26}$

In Tertullian, wie übrigens auch in Hieronymus und Augustin, sieht Auerbach einen hervorragenden Verteidiger des „figuralen Realismus, das heißt die grundsätzliche Aufrechterhaltung des geschichtlichen Wirklichkeitscharakters der Figuren [...]“. ${ }^{27}$ Wie seine griechischen Vorgänger ${ }^{28}$ vertritt Tertullian die These, dass Moses und die Propheten älter seien als die Schriftsteller der Griechen. Das Christentum stellt er als Erbe des Judentums dar, in Christus habe sich die Prophezeiung des Alten Testaments auf einen Erlöser erfüllt. ${ }^{29}$ Damit ist, was Auerbach mit aller Deutlichkeit

22 Tert., Anim. 43. Zitiert nach: Tertullians sämtliche Schriften, Bd. 2: Die dogmatischen und polemischen Schriften, aus dem Latein. übers. v. K. A. H. Kellner, Köln 1882, S. 355.

23 Auerbach (s. Anm. 8), S. 451, Anm. 20; vgl. Auerbach (s. Anm. 6), S. 51f. Auerbach macht an dieser Stelle eine philologische Anmerkung zu figuraretur, was hier zugleich „gebildet“ und „figuriert“ bedeutet.

24 Auerbach (s. Anm. 8), S. 451.

25 Tert., Fug. 11.

26 Tert., Adv. Marc. 4,40,3: Corpus suum illum fecit „Hoc est corpus meum“ dicendo, id est „figura corporis mei“. Figura autem non fuisset, nisi veritatis esset corpus. - „Er machte es [sc. das Brot] zu seinem Körper, indem er sagte, ,das ist mein Körper, es ist die Figur meines Körpers‘. Denn eine Figur kann nicht sein, ohne die Wahrhaftigkeit eines Körpers.“ Übersetzung H. M. Zilling. - Ceterum vacua res, quod est phantasma, figuram capere non posset. Aut si propterea panem corpus sibi finxit, quia corporis carebat veritate, ergo panem debuit tradere pro nobis. Faciebat ad vanitatem Marcionis, ut panis crucifigeretur. [...] non intelligens veterem fuisse istam figuram corporis Christi, dicentis per Hieremiam: Adversus me cogitaverunt cogitatum dicentes: Venite, coiciamus lignum in panem eius, scilicet crucem in corpus eius.

27 Auerbach (s. Anm. 6), S. 187.

28 Tert., Apol. 19,1; Eus., Pr. ev. IX,7,1; Just., Apol. I,44,8; 54,5; Tat., Orat. 31; 35-41; Theoph. Ant., Autol. 3,16-29.

29 Tert., Apol. 21. 
benennt, „durch die Methode der umdeutenden Interpretation das Alte Testament als Volksgeschichte und Gesetz der Juden entwertet [...]““, ${ }^{30}$ zudem werden „dessen Episoden als Figuren oder Realprophezeiungen der Ereignisse im Neuen gedeutet“ “ ${ }^{31}$

So wie schon an dem Beispiel Josua-Jesus dargestellt, verweist Auerbach auf die in besonderer Weise bei Tertullian entwickelten Figura-Vorstellungen und die Verwirklichung historischer Tiefenbewegungen in der christlichen Geschichtsbetrachtung, welche einer heilsgeschichtlichen Orientierung gehorchen. Auerbachs weitere Analyse setzt in dem berühmten Fortunata-Kapitel an. ${ }^{32}$ Die Textreferate und literaturwissenschaftlichen Analysen gerinnen in der Beschreibung dessen, was Auerbach als „Veränderung der alltäglichen Tiefe“ bezeichnet hat. ${ }^{33}$

\section{Von Petrons Gastmahl zum Markusevangelium}

Auerbachs Analyse basiert auf seiner sozialgeschichtlichen Deutung der neureichen Gesellschaft an der Tafel des Trimalchio, gezeichnet durch die erzählende Figur des Encolpius, im direkten Vergleich mit der Schilderung der Verleumdungsgeschichte des Petrus im Markusevangelium. ${ }^{34}$

Das Thema von Encolpius' Tischgenossen ist der Reichtum und die Unbeständigkeit des Lebens, dessen ganze Grundlage ein neu erworbener, also traditionsloser Wohlstand ist. Trimalchio und Fortunata sind extreme Exponenten einer „Freigelassenenklasse“ im Rom des ersten nachchristlichen Jahrhunderts. Sie haben, wie der Name von Trimalchios Frau, Fortunata, es verkündet, als Händler und Spekulanten „Glück gehabt“. Auerbach führt aus, dass das Glück, genauso wie das Unglück, in der griechischen und älteren römischen Literatur als ein von außen hereinbrechendes Schicksal verstanden wurde, wobei Petrons Glücksjägergesellschaft doch eine gänzlich neue Perspektive einnimmt. Anders als die exorbitanten Einzelschicksale antiker Tragödiengestalten teilen die antiken Aufsteiger des Petronius ein Gruppenschicksal, das eine höchst praktisch-irdische und durchaus innergeschichtliche Anschauung der „Schicksalswendung“ zeige. ${ }^{35}$

Anders bei Homer: Diesem dient die Schilderung der Herkunft stets der Darlegung einer weit zurückreichenden aristokratischen Traditionslinie, welche die unveränderlichen Werte einer Adelsgesellschaft heroisch verklärt und in unsterblicher Lied-

30 Auerbach (s. Anm. 6), S. 51.

31 Auerbach (s. Anm. 6), S. 75.

32 Auerbach (s. Anm. 6): Dort (Kap. II) setzt er drei annähernd zeitgenössische Textpassagen aus dem ersten und dem beginnenden zweiten nachchristlichen Jahrhundert miteinander in Beziehung. Zunächst betrachtet er Petrons romanhafte Episode aus dem Gastmahl des Trimalchio (Petron. $37 \mathrm{f}$.), dann eine Rede in den Annalen des Tacitus (Ann. I,17ff.) und schließlich die Verleugnung des Petrus aus dem Markusevangelium (Mk 14,66).

33 Auerbach (s. Anm. 6), S. 37-42.

34 Petron. $37 \mathrm{f}$.

35 Auerbach (s. Anm. 6), S. 33. 
form wiedergegeben hat, bemerkt Auerbach. ${ }^{36}$ Petron dagegen zeigt uns scharf wie auf einem Foto antiken Realismus. Dabei bleibt er völlig auf der Oberfläche, denn obgleich er dramatische Schicksalsschläge beleuchtet, berühren diese kaum.

Petronius legt auf die zeitgeschichtliche Seite seines Werkes keinen Wert. Hätte er es getan, hätte er die einzelnen Verhältnisse und Ereignisse mit bestimmten politischen-ökonomischen Lagen der ersten Kaiserzeit verknüpft, so wäre vor dem Auge des Lesers ein geschichtlicher Hintergrund entstanden, den die Erinnerung ergänzt hätte [...]. ${ }^{37}$

Ich verkürze, dass Auerbach mit dem Begriff der „Veränderung der alltäglichen Tiefe“ eigentlich einen historisch-analytischen Eingriff an der Literatur vornimmt, indem er einen fundamentalen Gegensatz zwischen der pagan-antiken und der frühchristlichen Literatur beschreibt: hier die historische Statik der Tiefenschichten, auf deren unveränderlichem, sozialgeschichtlichen Fundament die antike Literatur ruhe, dort das umwälzende Konzept der christlichen Heilsgeschichte, die, in einfacher Sprache verfasst, eine vertikale historische Linie hin zum Erlöser festlege.

Der Kirchenvater Eusebius schreibt passend dazu in seiner Kirchengeschichte:

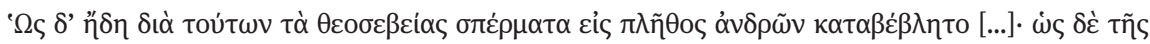

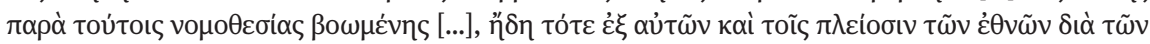

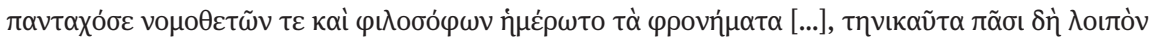

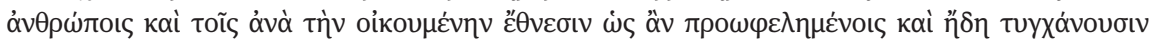

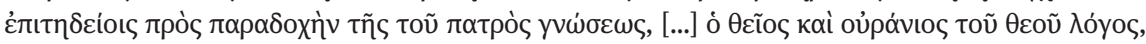

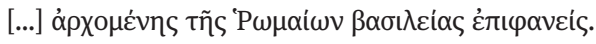

Erst als nun durch diese Gottesfreunde die Samen der Gottesfurcht in die Masse getragen wurden [...], erst als durch das Bekanntwerden der jüdischen Gesetze [...] infolge der Bemühungen von Gesetzgebern und Philosophen, die überall auftraten, zahlreiche Völker gesitteter wurden [...], erst jetzt, zu Beginn des römischen Kaiserreiches [weltgeschichtlicher Bezug], erschien allen übrigen Menschen und den Heiden des ganzen Erdkreises, da sie vorbereitet und bereits fähig waren, die Erkenntnisse des Vaters anzunehmen, [...] der erhabene und himmlische Logos Gottes in Menschengestalt..$^{38}$

Diese Konzeption war - trotz des Versuches von christlicher Seite, eine dynamische, ungebrochene Entwicklung aufzuzeigen und zu erklären - für Heiden wohl kaum akzeptabel.

Auerbach ist darin Recht zu geben, dass etwa die Misericordia mit deklassierten Menschen und ein Verständnis der Oberschicht mit den humiliores zumindest nicht grundsätzlich existiert haben, weil die Distinktionsbarrieren nahezu unüberwindlich waren. Vor diesem Hintergrund lesen wir mit den Evangelien eine ganz andere, neue

36 Auerbach (s. Anm. 6), S. $30 \mathrm{f}$.

37 Auerbach (s. Anm. 6), S. 35.

38 Eus., Hist. eccl. I,2,22f. Übersetzung nach: Des Eusebius Pamphili Bischofs von Cäsarea Kirchengeschichte, aus dem Griech. übers. v. P. Häuser (BKV, 2. Reihe, Bd. 1), München 1932, S. $23 \mathrm{f}$. 
Literatur. Und so ist etwa die Verleumdungsgeschichte des Petrus im Markusevangelium tatsächlich eine andere Art von Geschichte:

Petrus, auf dessen eigenen Bericht [so Auerbach] die Erzählung zurückgehen dürfte, war ein Fischer aus Galiläa, einfachster Herkunft und einfachster Bildung [...]. Aus der beliebigen Alltäglichkeit seines Lebens wird Petrus zu der ungeheuersten Rolle aufgerufen [...]. ${ }^{39}$

Faktisch handelt es sich um eine folgenreiche Polizeiaktion unter alltäglichen Personen aus dem Volk, mit einem zum auferstandenen Gottessohn gewordenen Antihelden, der aus der Schwäche und dem elenden Kreuzestod heraus seine Stärke bezieht, eine vorher ungekannte Konzeption.

\section{Die „Torheit des Kreuzes“ als Heldengeschichte?}

Der christliche Glaube an das Kreuz war für die Heiden nicht nur skandalös, sondern vor allem eine Absurdität, eine Torheit, denn sowohl Griechen, Römer als auch Juden

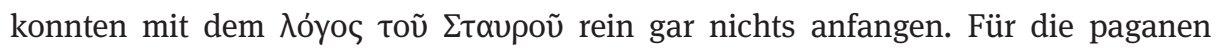
Zeitgenossen der Frühchristen war deren Festhalten an einem solchen Glauben nichts anderes als Torheit, ${ }^{40}$ galt doch die Kreuzesstrafe als schlimmste Strafe, als Strafe für Sklaven und peregrini, und das Kreuz selbst, crux, als Schimpfwort und Fluch, weshalb „ein gekreuzigter Messias, Gottessohn oder Gott für sie alle ein Widerspruch in sich selbst, Anstoß und Torheit bedeuten musste“..$^{41}$ In diesem Kontext steht der Kommentar des Origenes gegen die Anfechtung des christlichen Glaubens an den Gekreuzigten, der den schändlichsten Tod, mors turpissima crucis, erlitten hat. ${ }^{42} \mathrm{Im}$ Passionsbericht der Evangelien hat sich der Schock über den gewaltsamen öffentlichen Tod Jesu erhalten. Das Markusevangelium endet sogar in seiner ursprünglichen kürzeren Fassung mit dieser Erschütterung, dort heißt es, dass die Frauen, nachdem

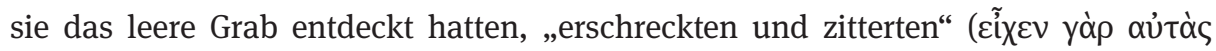

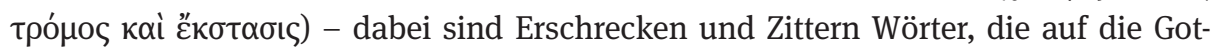
tesgegenwart verweisen..$^{43}$ Statt des misshandelten Körpers befand sich nämlich ein hell gekleideter, strahlender Jüngling im Grabraum.

Der markinische Schluss macht deutlich, dass gleichzeitig mit dem „Wort vom Kreuz“ eine Heldengeschichte beginnt. Der Gekreuzigte besiegt den Tod durch die Auferstehung und wird zum Retter der Menschheit. Mit dieser Botschaft beginnt die

39 Auerbach (s. Anm. 6), S. 44 f., zu Mk 14,66.

40 Z.B. Just., Apol. I,13,4. Hierzu und zum Folgenden H. M. Zilling, Jesus als Held. Odysseus und Herakles als Vorbilder christlicher Heldentypologie, Paderborn 2011, S. 39-40; 46.

41 M. Hengel, Mors turpissima crucis. Die Kreuzigung in der antiken Welt und die „Torheit“ des „Wortes vom Kreuz“, in: J. Friedrich u.a. (Hrsg.), Rechtfertigung. Festschrift für Ernst Käsemann zum 70. Geburtstag, Tübingen/Göttingen 1976, S. 125-184, hier S. 131.

42 Siehe den Verweis auf Orig., Comm. in Mt 27,22 ff. bei Hengel (s. Anm. 41), S. 125, Anm. 1

43 Mk 16,18; 16,1-8. 
Erfolgsgeschichte des Christentums. Anders gewendet, die Umwidmung der mors turpissima crucis in ein Tropaion, ein Siegeszeichen, schafft erst das Bild des heroischen und mächtigen Gottessohnes. ${ }^{44}$ Dabei gelingt den Christen nicht nur eine außergewöhnliche Umdeutung der Gestalt des Gekreuzigten, sondern auch der Umstände seines Todes: Das leere Grab und die Erscheinungen des Auferstandenen, die Himmelfahrt und der Sitz zur Rechten Gottes erinnern einerseits an pagane und alttestamentliche Bezüge und unterscheiden sich andererseits grundlegend in ihrer heilgeschichtlichen Bedeutung und Interpretation von diesen und erschaffen so etwas Neuartiges.

\section{Das leere Grab und der Auferstandene}

Das leere Grab ist Voraussetzung für das Wunder der Auferstehung und den Osterglauben, ist es doch gleichsam Beweis und notwendige Bedingung für den Glauben an die leibliche Auferstehung Jesu. Da das leere Grab zwar in den Evangelien, aber noch nicht in den früher entstandenen Schriften, insbesondere den paulinischen Briefen genannt wird, liegt die Vermutung nahe, dass die Bedeutung des leeren Grabes überhaupt erst durch den Glauben an die Auferstehung wichtig wird. ${ }^{45}$ Der Auferstehungsglauben birgt indes jede Menge Schwierigkeiten für seine Verkündiger und Anhänger. Gleichzeitig festigt er den Zusammenhalt der frühen Gemeinden enorm. ${ }^{46}$

Die Auferstehung am dritten Tag gewinnt im Licht der jüdischen Tradition ein anderes Gewicht und eine neue Konnotation, wenn man bedenkt, dass nach dem jüdischen Glauben die Seele den Körper erst am dritten Tag endgültig verlasse und somit das Antlitz des Toten danach nicht mehr erkennbar sei. Wenn nach der Schilderung des Evangeliums nach Markus die Frauen also den Leichnam Jesu am dritten Tag besuchen, dann auch, um sicher zu gehen, dass sie ihn noch finden, um ihn in später in ein anderes Grab umlegen zu können, da er als Gekreuzigter nicht an einem ehrenvollen Platz begraben werden durfte. ${ }^{47}$

Es gibt nur wenige Beispielberichte von leeren Gräbern aus der antiken Literatur. Fündig werden wir zunächst im Alten Testament. So ist der entrückte Henoch schlicht nicht mehr da und hat dementsprechend kein Grab (Gen 5,24) und die Suche nach Elias bleibt auch nach drei Tagen noch erfolglos (2 Kön 2,17). In diesen Zusammenhang

44 Just., Apol. I,55,3.

45 M. Wolter, Die Auferstehung der Toten und die Auferstehung Jesu, in: E. Gräb-Schmidt, R. Preul (Hrsg.), Auferstehung (Marburger Theologische Studien 116), Leipzig 2012, S. 13-54; hier S. 41f. Auferstehung und die Visionen vom Auferstandenen: S. 45 ff. Zur Bedeutung des Auferstehungsglaubens: S. 52 .

46 Vgl. dazu J. Thiessen, Die Auferstehung Jesu in der Kontroverse. Hermeneutisch-exegetische und theologische Überlegungen, Zürich/Berlin 2009, S. 55 ff., mit einem umfassenden Forschungsüberblick zu den Auslegungen des leeren Grabes. C. A. Evans, Jesus and his World. The Archeological Evidence, London 2012, S. 113-140, zu den archäologischen Funden und jüdischen Traditionen zur Zeit Jesu. 47 Evans (s. Anm. 46), S. 116f.; 139. 
gehöre, so Wolter, ebenfalls, dass nach Dtn 34,5f. das Grab des Moses nicht bekannt sei. ${ }^{48}$ Ein Leichnam und das dazugehörige Grab fehlen ebenso in der paganen Herakles-Mythologie: Nach Diodorus Siculus IV,38,5 wurden die Knochen des Heros nach seinem Tod vergeblich gesucht und ,als sie nicht einen einzigen Knochen fanden, nahmen sie an, dass Herakles [...] von den Menschen zu den Göttern versetzt worden sei““. ${ }^{49}$ Herakles, der sich selbst den Flammen übergibt und in den Himmel aufsteigt (s. u.), und Moses, dessen Grabstätte unbekannt ist, sind die beiden bekanntesten Figuren aus der Umwelt der frühen Christen, deren Gräber leer oder unauffindbar waren, wobei beide - wenn auch in unterschiedlicher Weise - eine figurale oder gestaltende Vorbildfunktion für die Geschichte Jesu nahelegen könnten.

Von Moses kann Josephus bezogen auf seine Abwesenheit auf dem Berg Sinai (Ex 32,1) berichten:

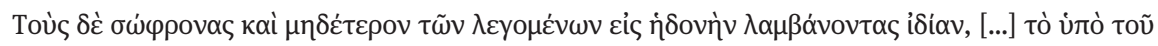

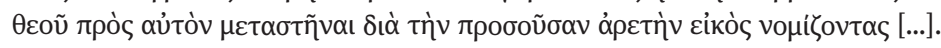

Die Klugen aber, denen keine von beiden Ansichten gefiel, hielten es [...] für wahrscheinlicher, dass er von Gott zu ihm selbst versetzt worden sei wegen der offensichtlichen Tugend [...]..$^{50}$

Und aufgrund des fehlenden Grabes erklärt Josephus:

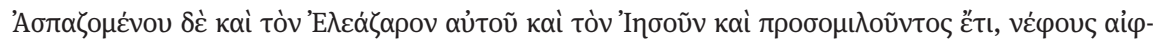

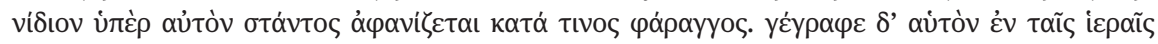

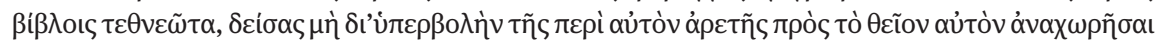

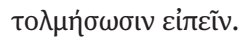

Darauf umarmte er [sc. Moses] Eleazar und Josua, und während er noch sprach, blieb plötzlich eine Wolke über ihm stehen, und er entschwand wie in einer Schlucht. In den heiligen Büchern aber hat er geschrieben, er sei gestorben, weil er fürchtete, man könnte wagen zu sagen, er habe sich wegen der Außerordentlichkeit seiner Tugend zur Gottheit entfernt. ${ }^{51}$

Die exzeptionelle Bedeutung des Moses ist in den verschiedenen kulturellen Kontexten immer auf seine Nähe zu Gott, seine Gesetzgebung, seine Bedeutung für das Gottesvolk, die in ihm zum Ausdruck kommende Folgenhaftigkeit des göttlichen Willens, des Zorns gegen das ungehorsame Volk, aber auch in seiner Entrückung zu sehen.52

Diese Fälle haben gemeinsam, dass man nach dem Leichnam fahndet und ihn nicht findet, daraus auf die Entrückung und implizit auf ein leeres Grab schließt. Mit der Sicht auf Herakles, seine göttliche Herkunft, seinen Todeskampf, die Himmelfahrt

48 Diese Beispiele und noch weitere Quellenzitate bei Wolter (s. Anm. 45), S. 22-29; S. 27 zu Moses.

49 Wolter (s. Anm. 45), S. 23.

50 Ios., Ant. III,97. Zitiert nach Wolter (s. Anm. 45), S. 27.

51 Ios., Ant. IV,326. Zitiert nach Wolter (s. Anm. 45), S. 27.

52 Vgl. dazu etwa J. Assmann, Religion und kulturelles Gedächtnis. Zehn Studien, 2. Aufl., München 2004, S. 29 ff., zur Konfiguration von Erinnerung in der Abschiedsrede des Moses (Dtn 4,9; 6,10 - 12) und S. 162, zum Zorn des Moses beim Anblick seines Volkes, das um das goldene Kalb tanzt, als er mit den Gesetzestafeln zu ihnen zurückkehrt. Zur Entrückung des Moses siehe Wolter (s. Anm. 45), S. 27. 
und Apotheose erreichen wir einen paganen Kontext, respektive eine pagane Figura, wenngleich Auerbach nur alttestamentliche Gestalten, auf die die Christen Bezug nehmen können, als Figurationen beschreibt. Die Ausweitung des Begriffs ist dennoch möglich und denkbar und soll im folgenden Abschnitt bezogen auf Herakles und Polykarp als These vertreten werden.

Bezogen auf die Besonderheit der christlichen Deutung verhindert möglicherweise einerseits das leere Grab einen Heroenkult um die Gestalt Jesu nach paganem Vorbild, da ja ohne eine Grabstätte der übliche Grabkult nicht möglich ist, und andererseits verweist es auf die Auferstehung und Himmelfahrt Jesu, mithin auf seine göttliche Natur und seine zentrale Rolle in der Heilsgeschichte, die über die Bedeutung des paganen Heros für den Menschen weit und fundamental hinaus geht. ${ }^{53}$ So ist wiederum die christliche Auferstehungshoffnung schon im Alten Testaments vielfach angelegt (Jes 25,8; Ps 22,28-32; Dan 12,2! u. a.), wird aber letztendlich erst durch die leibliche Auferstehung Jesu begründet. ${ }^{54}$ Dabei stellte schon Kelsos nach dem Zeugnis des Origenes die Frage, warum die Christen die Auferstehung Jesu nicht so deuten wie etwa die Erscheinungen des Pythagoras, des Orpheus, des Protesilaos, Theseus oder Herakles. ${ }^{55}$ Betz vertritt dazu die These, die Christen, die in einer Umwelt lebten, in der sich die Heroenverehrung großer Beliebtheit erfreute, hätten eine Heroisierung Christi bewusst abgelehnt, wenn auch die Passionserzählung und die Apostelgeschichte noch Anzeichen einer beginnenden Heroisierung des Gekreuzigten enthielten. ${ }^{56}$

Auch Herakles hinterlässt wie Moses kein Grab (zumindest nicht in der Fassung nach dem Hercules Oetaeus) und gilt trotzdem als Heros und bemerkenswerterweise wie Jesus nach seiner Himmelfahrt als Gott. Darin ist er jedoch als Heros und Gott ein Einzelfall in der paganen Mythologie. Eine Heroisierung ist also, wie die Verehrung des Herakles zeigt, durch das leere Grab noch nicht wirklich ausgeschlossen. Dies sei ergänzend zu Betz angemerkt, der besonders in diesem Umstand und in der zeitlichen Begrenzung der nachösterlichen Erscheinungen einen bewussten Entschluss gegen die schon begonnene Heroisierung Jesu sieht. Das leere Grab verweist sicherlich auf die Entrückung und Auferstehung des Verstorbenen und eröffnet damit den Schritt, die Apotheose zu erklären: Immerhin vollzieht sich so, dass aus dem gemarterten MessiasMenschensohn am Kreuz der Gottessohn hervortritt.

In einer weiteren Auslegung des Figura-Begriffes von Auerbach könnte man sagen, dass es den frühen Christen naheliegend erscheinen musste, und zwar aufgrund einer Vielzahl von Vorbildern aus den paganen und jüdischen Mythen, Jesus als Heros zu begreifen. So auch Betz: Der ungerechte gewaltsame Tod, der durch die göttliche Herkunft und Auferstehung in ein Heilsereignis transformiert wird sowie die Him-

53 Vgl. dazu auch Betz (s. Anm. 16), S. 151.

54 Thiessen (s. Anm. 46), S. 150 f. Thiessen hält es für unwahrscheinlich, dass die neutestamentliche Hoffnung der leiblichen Auferstehung auf hellenistische Einflüsse zurückzuführen ist, vielmehr sieht er sie in der Tradition des Alten Testaments begründet.

55 Betz (s. Anm. 16), S. 128. Vgl. Orig., Cels. II,55.

56 Betz (s. Anm. 16), S. 129; $148 \mathrm{ff}$. 
melfahrt sollten dabei mitbedacht werden (Lk 24,26; 24,51). ${ }^{57}$ Hinzu kommen die Kindheitserzählungen und Wundergeschichten, die nicht nur Vorbilder im paganen Mythos, sondern ebenso in den Schriften des Alten Testaments haben. ${ }^{58}$ Das Muster, nach dem sich Epiphanien ereignen, macht die Bezüge deutlich, so z.B. im Lukasevangelium bei den Berichten über die Emmausjünger oder die Erscheinungen des Auferstandenen vor den Elfen: Die plötzliche Erscheinung des Auferstandenen ruft zunächst Furcht hervor (Lk 24,36; vgl. insgesamt hierzu und zum Folgenden Philostrats Heroikos 21,6-8; 22,10-22), gefolgt vom Moment des Wiedererkennens und der schwindenden Zweifel, wobei ungläubiges Berühren und Betasten eine Rolle spielt (Lk 24,39), schließlich findet die Freude über die Wiederkehr des Auferstandenen in der Mahlgemeinschaft ihren Ausdruck, gefolgt von seinem Verschwinden (Lk 24,30 f.). Dieses Muster ist sowohl von fundamentaler Bedeutung für die Gemeindebildung als auch die Mission, denn die verunsicherten und abgefallenen Jünger werden auf diese Weise zurückgewonnen und berichten über die Epiphanie des Heros-Christus. Gleichzeitig spielt es eine konstitutive Rolle für die Kultgründung, welche wiederum maßgeblich mit der Mahlgemeinschaft verknüpft ist. ${ }^{59}$

Entscheidend ist, hierin folge ich Betz, dass die Evangelisten sich jedoch letztendlich gegen eine Heroisierung Jesu nach paganem Vorbild entschieden haben - und damit den einzigartigen Anspruch des Gekreuzigten begründeten. Dabei war das leere Grab wie in Mk 16,6 von zentraler Bedeutung, machte dieses doch „einen Heroenkult am entscheidenden Punkt unmöglich““. ${ }^{60}$ Die Phase der Epiphanien schließlich begrenzten die Evangelisten auf die Zeitspanne vor der Himmelfahrt.

Stattdessen wurde die Auferstehung Jesu durch eine Erhöhungschristologie interpretiert, nach der er seinen Platz als Kosmokrator zur Rechten Gottes einnahm. Eine solche Christologie hatte zur Folge, dass seine universale Gegenwart mit dem Heiligen Geist und dem Wort der Verkündigung verbunden wurde. ${ }^{61}$

57 Hierzu und zum Folgenden siehe Betz (s. Anm. 16), S. 149.

58 So hat etwa der Jesusknabe im Kindheitsevangelium des Thomas durchaus Ähnlichkeiten mit dem jungen Herakles. Siehe Evangelium Thomae de infantia Salvatoris/Kindheitserzählung des Thomas 3,3; 4,1 f.; vgl. 7,2; 9,3 (Evangelia infantiae apocrypha/Apocryphe Kindheitsevangelien, übers. und eingel. von G. Schneider, Freiburg u.a. 1995 [Fontes Christiani 18], S. 147-171). Zu Herakles siehe etwa Theokr. 24; Pind., N. 1,35-70; Diod. 3,67; Apollod. 2,4,9. Vgl. dazu Zilling (s. Anm. 40), S. 153 ff. Siehe außerdem S. 161-173: zum Vergleich der Geburtsgeschichten, S. 173-176: zur Gottessohnschaft. Die Wundergeschichten greifen oft alttestamentliche Motive auf wie etwa die Speisung der 5000 (Mk 6,3544 par Mt 14,13-21; Lk 9,10 - 17; Joh 6,1-13), die an die wunderbare Brotvermehrung des Elisa erinnert, der hundert Männer mit zwanzig Gerstenbroten sättigt (2 Kön 4,42-44), oder die Totenerweckung der Tochter des Synagogenvorstehers Jairus (Mk 5,21; 5,35-43), des Jünglings zu Naïn (Lk 7,11-17) sowie die Auferweckung des Lazarus (Joh 11,1-45), diese greifen die Auferweckung des Sohnes einer Witwe durch Elias auf (1 Kön 17,17-24).

59 Vgl. dazu Betz (s. Anm. 16), S. 138, Anm. 39.

60 Betz (s. Anm. 16), S. 151.

61 Betz (s. Anm. 16), S. 151. 
In der Auseinandersetzung der Theologen über den Auferstehungskontext zeigt sich die Notwendigkeit die, wie Paulus es ausdrückt, Torheit des Wortes vom Kreuz zu

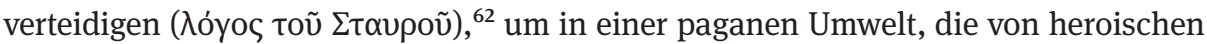
Mythen belebt wird, zu bestehen. So lassen die Passionserzählungen Ansätze einer Heroisierung Jesu erkennen, die paganen Vorbildern folgt, wie auch die Geschichte des von einer Jungfrau geborenen Gottessohnes, der schließlich nach großem Leiden in den Himmel auffährt, dem Mythos des Herakles ähnelt. ${ }^{63}$ Doch werden viele Ansätze einer Heroisierung des Gekreuzigten schließlich nicht genutzt, obwohl oder gerade weil sie in der Umwelt des frühen Christentums so präsent waren. Denn letztendlich unterscheidet sich die christliche Botschaft grundlegend vom Heroenkult in der Heilsund Erlösungstheologie. Die frühchristlichen Schriftsteller wählen (und darin ist Auerbachs Beobachtung zu bestätigen) neue Formen, um die Inhalte ihres Glaubens darzustellen. Sie wählen z. B. bei der Führung des Altersbeweises die Hinweise der Propheten des alten Bundes als Deutungszusammenhang, die auf Jesus hinweisen, und eben nicht die Götter und Helden ihrer paganen Umwelt. ${ }^{64}$

Das Besondere an Auerbachs Betrachtung ist, dass er die Sicht auf die Vielzahl der Kontexte lenkt, in die die Gestalt Jesu nach christlich-hermeneutischer Tradition eingebettet wird, wenn er auch den Figura-Begriff hauptsächlich auf die innerchristlichen Interpretationszusammenhänge beschränkt.

Selbst in dieser möglicherweise bewussten Abgrenzung von den alten Göttern, Heroen und Mythen lässt sich trotzdem bemerken, dass die Beschränkung der Christen auf die Deutung des Neuen Testaments als Erfüllung des Alten nicht verhindern konnte, dass 1) alle kulturellen Kontexte des Alten Testaments mit einflossen, somit auch alle paganen Einflüsse auf die Entstehung des Judentums und 2) auch die frühen Christen, die Evangelisten, Apostel, Missionare und Kirchenväter immer ein Teil ihrer Umwelt, ihres kulturellen Kontextes, eben auch der paganen Mythen und Götterwelt waren. ${ }^{65}$ Doch sie haben sicherlich versucht - das zeigen die Auseinandersetzungen mit der paganen Umwelt - sich von ihrem kulturellen Kontext abzuheben, sie erschaffen eine neue Erinnerungsgemeinschaft, eine neue Deutung ihrer Geschichte als Volk Gottes und damit einen neuen ,Mythos' mit eigenen Heroisierungsmechanismen.

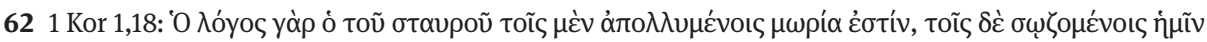

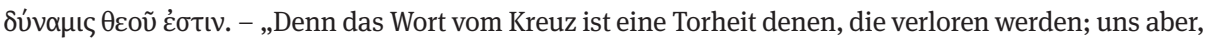
die wir selig werden, ist’s eine Gotteskraft.“ Vgl. Zilling (s. Anm. 40), S. 39 ff.

63 Betz (s. Anm. 16), S. 149. Zilling (s. Anm. 40), S. 153-188.

64 Vgl. die Gottesknechtslieder bei Jesaja: Während im Alten Testament der Gottesknecht im engeren Sinn für von Gott in besonderer Weise erwählte Menschen stand (Jes 42,1-9; 49,1-9; 50,4-9; 52,1353,12), wird im Neuen Testament Jesus typologisch als Gottesknecht gedeutet (Mt 12,18; Lk 17,22-37). 65 Siehe dazu Assmann (s. Anm. 52), S. 18f.: „Und dazu [zum Erinnern] bedienen sich beide, das Kollektiv und der Einzelne, des Archivs der kulturellen Traditionen, des Arsenals der symbolischen Formen, des ,Imaginaires‘ der Mythen und Bilder, der ,Großen Erzählungen', der Sagen und Legenden, Szenen und Konstellationen, die nur immer im Überlieferungsschatz eines Volkes lebendig und reaktivierbar sind.“ 
Am Ende wird das Kreuz - Symbol des schändlichsten aller Tode - zum Siegeszeichen und der Gekreuzigte zum Triumphator.

Dass Jesus als Mensch gelitten hat und gestorben ist, ist seitdem eine nach menschlichem Ermessen unfassbare Geschichte (vgl. den Ausspruch credo quia absurdum, der sinngemäß bei Tertullian auftaucht) ${ }^{66}$ und eine neue Heilslehre, die in der Auslegung durch die Evangelisten und die Kirchenväter im Rahmen der alttestamentlichen Heilsgeschichte verortet und figurativ gedeutet wird. Gleichzeitig dient die deutliche Herabsetzung und Geringschätzung etwa des paganen Gottessohnes Herakles durch die Kirchenväter dem Zweck, mögliche Parallelen zu verwischen und als unstatthafte These zu verwerfen, um so die Einzigartigkeit des christlichen Heilsgeschehens zu festigen. ${ }^{67}$ Tatsächlich lässt sich aber gerade abseits der bewussten Auseinandersetzung mit den paganen Vorbildern zeigen, wie weit die antiken Heroen und ihre Geschichten im Denken der christlichen Autoren verwurzelt waren.

\section{Der Tod des Märtyrers - Herakles und Polykarp}

Erstaunlich sind die Parallelen des heroischen Aufstiegs in der klassischen Heldengeschichte, auf die ich im Folgenden an zwei Beispielen, die auch als Erlöserfiguren gesehen werden können, eingehen werde: zum einen der heroische Menschenretter Herakles, zum anderen der „listenreiche“ Odysseus, der viel zu erdulden hat, am Ende seiner Irrfahrten aber die Heimat Ithaka findet.

Auf Herakles Tatenzyklus werde ich nicht näher eingehen, sondern seinen heroischen Todeskampf betrachten, welcher in der lange Zeit Seneca zugeschriebenen Tragödie Hercules Oetaeus beschrieben ist. ${ }^{68}$ Dort endet der Heros auf einem gigan-

66 Tert., Carn. 5,4 (CCSL 2,881,26-29): Crucifixus est dei filius; non pudet, quia pudendum est. Et mortuus est dei filius; credibile est, quia ineptum est. Et sepultus resurrexit; certum est, quia impossibile. „Gottes Sohn ist gekreuzigt; ich schäme mich nicht, weil es beschämend ist. Gottes Sohn ist gestorben: dies ist glaubwürdig, weil es unschicklich (ineptum) ist. Er wurde begraben und ist auferstanden: dies ist gewiss, weil es unmöglich ist.“ Übersetzung nach M. Fiedrowicz (Hrsg.), Handbuch der Patristik. Quellentexte zur Theologie der Kirchenväter, Freiburg 2010, S. 613, Nr. 778 mit Anm. 207: dort die Angabe der Parallelstellen und Literaturhinweise; besonders R. D. Sider, Credo quia absurdum?, Classical World 73 (1980), S. 417-419; siehe auch H. M. Zilling, Tertullian. Untertan Gottes und des Kaisers, Paderborn 2004, S. $176 \mathrm{ff}$.

67 So etwa Just., Dial. 67,2f.; 69,2ff. oder Tert., Nat. 2,14: Hercules’ Apotheose sei in Wahrheit eine Selbstrichtung und der Selbstmord eines Mörders gewesen; vgl. auch Min. Fel. 22,7; Firm., Err. 7,6. Vgl. dazu Zilling (s. Anm. 40), S. 189 ff. mit weiteren Belegen.

68 In der Forschung lange umstritten, geht man inzwischen davon aus, dass dieses Stück zu Unrecht Seneca zugeschrieben wurde. Trotzdem wird es zumeist mit den Stücken Senecas gemeinsam untersucht. Gewiss scheint, dass das Stück spätestens Anfang des 2. Jahrhunderts n.Chr. entstanden ist, was es in jedem Fall in die zeitliche Nähe der Entstehung der Evangelien rückt und seine Bekanntheit zur Zeit des Martyriums Polykarps zumindest möglich macht.Vgl. zunächst H. Canciks Beitrag „Seneca und die römische Tragödie“ in dem von Manfred Fuhrmann herausgegebenen Handbuch Römische Literatur, Frankfurt a. M. 1974, S. 251-260, der die Frage der Echtheit des Hercules Oetaeus als Aporie 
tischen Scheiterhaufen, um nach der Selbstverbrennung als Flammenbesieger und in den Himmel gefahrener vergöttlichter Heros einen neuen Anfang zu nehmen. ${ }^{69} \mathrm{Um}$ letzte Zweifel an seiner Apotheose zu zerstreuen, erscheint der Totgeglaubte vor seiner klagenden Mutter, somit bietet gerade diese Szene eine Parallele zur Auferstehung Christi. ${ }^{70}$ Herakles' stoische Haltung, so Nesselrath, transformiere das schuldbeladene Ende des Heros, mehr noch: „Die Tragödie wird von der Apotheose aufgehoben.“71

Eine erhabene Haltung im Tod findet sich außerdem nicht nur bei Sokrates, sondern bekanntermaßen, Nesselrath verweist darauf, ebenso in der stoischen Philosophie und als Topos in der christlichen Märtyrerliteratur - siehe z. B. die Schilderung des Martyriums des Polykarp. ${ }^{72}$ Hier wie dort betet der Heros-Martys auf dem Scheiterhaufen gleichsam in den geöffneten Himmel: „Ich komme, Vater.“ Mit diesem Ruf beginnen die Herakles-Verbrennung und das bei beiden stattfindende Flammenwunder. Auch der Zeuge und Autor des Martyriumsberichts Polykarps schreibt, dass dieser in den Himmel geblickt und gesprochen habe: „Herr, allmächtiger Vater/

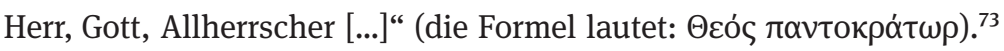

bezeichnet. Er hält daran fest, Senecas Beitrag für die Entwicklung der kaiserzeitlichen Tragödien hoch zu bewerten sowie im Hercules Oetaeus ein außerordentlich bedeutsames Zeugnis für das Verständnis der Heraklesreligion zu sehen. Das Werk ordnet er in die zweite Hälfte des ersten nachchristlichen Jahrhunderts ein. Weiterhin vergleiche zu den Senecatragödien O. Zwierlein, Kritischer Kommentar zu den Tragödien Senecas, Mainz/Stuttgart 1986, zum Hercules Oetaeus S. 313; 339. Siehe auch H.-G. Nesselrath, Herakles als tragischer Held in und seit der Antike, in: H. Flashar (Hrsg.), Tragödie. Idee und Transformation (Colloquium Rauricum 5), Stuttgart/Leipzig 1997, S. 307-331, S. 315.

69 Sen., Herc. 0. $1464-1472 ; 1594 ; 1615$ ff.; 1967 ff. Im Folgenden zitiert nach: Herkules auf dem Öta, in: Seneca. Sämtliche Tragödien. Lat. u. dt., Bd. 2, übers. u. erl.v.T.Thomann, Zürich/Stuttgart 1969, S. 257391.

70 So auch Nesselrath (s. Anm. 68), S. 317.

71 Nesselrath (s. Anm. 68), S. 318.

72 Nesselrath (s. Anm. 68), S. 317 ff. Das berühmteste Beispiel ist neben dem Tod des Sokrates gewiss der Tod des stoischen Philosophen Seneca, der sich in seinen Schriften oft mit dem rechten Sterben auseinandergesetzt hat. Siehe dazu etwa Sen., Epist. 26,10: Una est catena, quae nos alligatos tenet, amor vitae, qui ut non est abiciendus, ita minuendus est, ut si quando res exiget, nihil nos detineat nec inpediat, quo minus parati simus, quod quandoque faciendum est, statim facere. - „Es gibt nur eine Kette, die uns gefesselt hält, nämlich die Liebe zum Leben. Wir dürfen sie nicht von uns weisen, aber wir müssen ihren Druck mindern, damit uns unter dem Druck der Umstände nichts zurückhalte und hindere bereit zu sein, unverzüglich das zu tun, was einmal doch geschehen muss.“ 54,7: Hoc tibi de me recipe: non trepidabo ad extrema, iam praeparatus sum, nihil cogito de die toto. - „Lass Dir von mir sagen: ich werde vor dem letzten Augenblick nicht zittern, ich bin schon bereit, ich rechne nie mit einem ganzen Tag, den ich etwa noch zu leben hätte.“ Übersetzung nach: Lucius Annaeus Seneca. Philosophische Schriften, Bd. 3: Briefe an Lucilius, übers., m. Einl. u. Anm. vers.v. O. Apelt, Wiesbaden 2004, S.100;188. Mart. Polyc. 12,1. Der Text nach: A. Lindemann, H. Paulsen (Hrsg.), Die Apostolischen Väter, Tübingen 1992, S. 244-285.

73 Sen., Herc. O. 1726; Mart. Polyc. 14,1; vgl. Offb 1,8; 4,8; 16,7; 21,22; s. P. Guyot, R. Klein (Hrsg.), Das frühe Christentum bis zum Ende der Verfolgung, Darmstadt 1997, S. 333, Anm. 51. 
Herakles gehorcht in der Annahme des Todes seiner göttlichen „Bestimmung“ - so wird der Martertod auch im Martyrium Polycarpi genannt. ${ }^{74}$ Herakles hadert nicht mit seiner Bestimmung, sondern folgt ihr, sobald er sie erkannt hat. Epiktet formuliert daraus die Lehre: Wie Herakles als Zeussohn seinen göttlichen Auftrag annimmt, so sollen die Menschen die Lebensbedingungen annehmen, unter denen sie leben. Die imitatio des Dulders wird am Beispiel des Herakles zum ethischen Gebot erhoben, der einst wilde Heros zum weisen, durch seine Frömmigkeit standhaften Vorbild umgedeutet. $^{75}$

Man könnte dies auch so formulieren: Das mimetische Konzept ist dem ImitatioMotiv der Märtyrer verwandt. Dazu heißt es im Martyriumsbericht des Polykarp, der von dem zentralen Gedanken der Nachfolge Christi beherrscht wird:

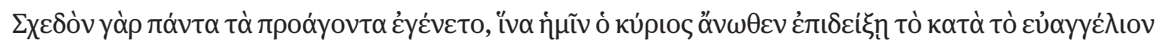

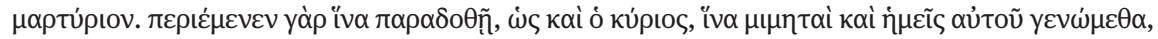

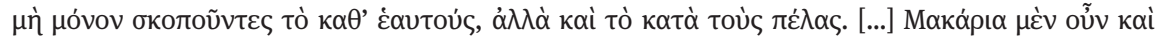

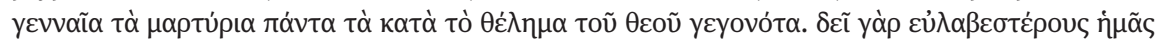

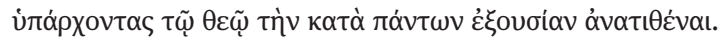

Denn beinahe alles, was vorging, geschah, damit uns der Herr noch einmal das Schauspiel des Martyriums, wie es im Evangelium erzählt ist, vor Augen führe. Denn er wartete, bis er ausgeliefert wurde, wie auch der Herr, damit auch wir seine Nachahmer werden, ,indem wir nicht nur unser eigenes Wohl, sondern auch das des Nächsten im Auge haben“. [...] Segensreich und ehrenvoll waren alle Martyrien, wenn sie nach Gottes Willen geschahen; denn wenn wir gottesfürchtig sind, müssen wir Gott die Macht über alles zuschreiben. ${ }^{76}$

\section{So spricht Hercules:}

Iam virtus mihi / in astra et ipsos fecit ad superos iter. [...] Paterna caelo, pars data est flammis tua. [...] Virtus in astra tendit, in mortem timor.

Schon hat mein Heldentum mir den Weg zu den Gestirnen und den Überirdischen selbst bereitet. [...] Des Vaters Teil wurde dem Himmel, dein Teil [sc. der irdisch-mütterliche] den Flammen anheimgegeben [...]. Den Sternen strebt Heldentum, Furcht dem Tode $\mathrm{zu}^{77}$

74 Mart. Polyc. 6.

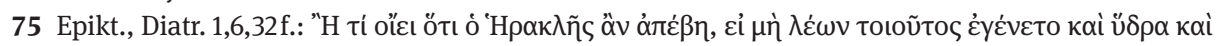

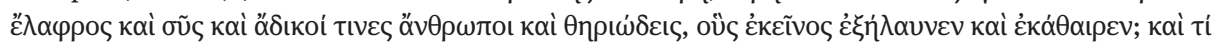

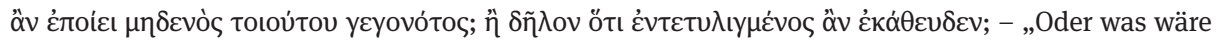
wohl aus Herakles geworden, wenn ihm nicht ein solcher Löwe begegnet wären und eine Hydra, ein Hirsch und ein Eber und manche verbrecherischen und wüsten Kerle, die er verjagte und ausrottete? Und was hätte er getan, wenn keins dieser Ungetüme existiert hätte? Dann hätte er sich doch sicher eingemummelt und geschlafen. “ Übersetzung nach: Epiktet, Teles und Musonius. Wege zu glückseligem Leben, übertr. u. eingel. v. W. Capelle, Zürich 1948, S. 174.

76 Mart. Polyc. 1,1-2,1.

77 Sen., Herc. O. 1942f.; 1968-1971. 
Alkmene, seine Mutter, wird zur Zeugin seiner Himmelfahrt:

[...] in astra fertur. Fallor an voltus putat / vidisse natum? misera mens incredula est. / Es numen et te mundus aeternum tenet, / credo triumphis.

Auf zu den Gestirnen fährt er. Täusche ich mich oder wähnt nur mein Auge, es habe den Sohn geschaut? Ein gramvoller Sinn ist ungläubig. Doch eine Gottheit bist du und auf ewig des Himmels Besitz: Ich glaube an deine Triumphe. ${ }^{78}$

Somit besingt sie den neuen Gott. ${ }^{79}$ Nachdem die Mutter das Zeugnis der Auferstehung und der Apotheose gegeben hat, folgt der Chor mit einem Lobpreis des Helden und seiner Anrufung als Schutzpatron (!):

Sed tu, domitor magne ferarum / orbis que simul pacator, ades; / nunc quoque nostras respice terras [...]. Fortius ipso genitore tuo / fulmina mitte.

Du großer Bezwinger von Ungeheuern und des Erdkreises Friedensbringer in einem, steh uns bei, auch jetzt sieh herab auf unsere Erde [...]. Machtvoller als dein Erzeuger selbst schleudere die Blitze. ${ }^{80}$

Man hat den Eindruck, Herakles werde hier regelrecht als Heiliger angerufen. Zusammengefasst ergibt sich, um auf Auerbach zurückzukommen, durchaus die Anschauung, dass einige Heroen als Präfigurationen christlicher Helden gedient haben könnten. Neben Herakles und Odysseus ist auch an Prometheus, besonders aber an Orpheus zu denken.

Prometheus hingegen wurde weniger intensiv von den Kirchenvätern aufgegriffen. Die Apologetik hebt darauf ab, dass Christus der wahre Prometheus sei (Tertullian, Apol. 18). Das Motiv des stellvertretenden Leiden zum Wohle der Menschen bietet einen weiteren Bezugspunkt, der Prometheus, um es mit Karl Marx zu sagen, „zum vornehmsten Heiligen und Märtyrer macht“. ${ }^{81}$ Prometheus, der Menschenfreund, leidet fest an den Felsen geschmiedet ohne Unterlass und ohne Aussicht auf Erlösung - in Lukians Prometheus spricht Merkur von einer Kreuzigung und Annagelung an den Felsen. Orpheus dagegen überwindet den Tod und verfügt über göttliche Wunderkräfte wie der Theios Aner ( $\theta \varepsilon \tilde{o}$ os ávń $\rho)$, der göttliche Mensch Jesus. So stellt etwa Eusebius im 3. Buch der Theophanie Jesus als wirkmächtigen Wundertäter und Heiland dar, durch den der Logos als musikalisches Instrument wirkt. Er heilt gleichsam die „rohen tierischen Leidenschaften der Seelen mit den Heilmitteln göttlicher Lehre und zeigt den kranken Seelen, [...] wie ein vorzüglicher Arzt durch ein ihnen verwandtes und ähnliches Hilfsmittel Gott im Menschen“, und er erweckt sogar Tote wieder zum Leben

78 Sen., Herc. O. 1978-1981. Siehe die Darstellung der Himmelfahrt des Herakles auf der Igeler Säule, Abb. 16 in Zilling (s. Anm. 40).

79 Sen., Herc. O. 1982.

80 Sen., Herc. O. $1989-1996$.

81 Dissertation über die „Differenz der demokritischen und epikureischen Naturphilosophie“, 1841, MEW Erg.-Bd. 1, S. 263. 
wie Lazarus. ${ }^{82}$ Auch Clemens von Alexandrien setzt in der Eröffnung seines Protreptikos dem Orpheus-Mythos den wahren Orpheus Christus entgegen - Christus ist hier gleichsam der bessere Orpheus:

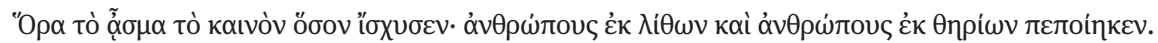

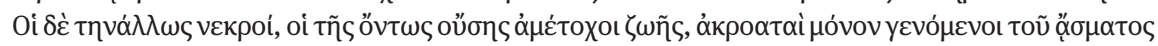

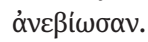

Sieh, was das neue Lied vollbrachte: Menschen hat es aus Steinen, Menschen aus Tieren gemacht. Und die sonst wie tot waren und keinen Anteil am wahren Leben hatten, sie wurden wieder lebendig, sobald sie nur Hörer des Gesanges geworden waren. ${ }^{83}$

Orpheus zähmt zwar die Tiere und sogar unheimliche Pflanzen, Christus dagegen „zähmt“ die Menschen. ${ }^{84}$ Clemens fragt seine Hörer: „Wie kommt es denn, dass ihr so leeren Mythen Glauben geschenkt habt?“85 Diese Frage demonstriert, dass in der Glaubensvermittlung immer wieder an den fundamentalen Mythen angesetzt wurde und gleichzeitig die Abgrenzung zwischen Christentum und Heidentum eine wichtige Rolle gespielt hat. Bei Justin wird die apologetische Abgrenzungstendenz besonders deutlich, er stellt nämlich den Tod des Orpheus durch Zerfleischung als „dämonisches Plagiat der Kreuzigung Christi“ dar. ${ }^{86}$

Mythos und Martyrium bilden, so meine These, eine literarische Kontinuität. Sie können deshalb so wirkmächtig sein, weil sie die Geschichten des Lebens und Sterbens nutzen. Der Martyriumsbericht der Christen kann dafür die bereits existierenden Muster und Topoi mit dem ganz eigenen Anliegen des neuen Glaubens füllen.

82 Eus., Theoph. III,39 (GCS Eusebius III/2,143,17-21). Zitiert nach der Übersetzung der syrischen Überlieferung nach W. Storch (Hrsg.), Mythos Orpheus, 3. Aufl., Leipzig 2001, S. 87 f. Dazu Markschies (s. Anm. 2), S. $240 \mathrm{f}$.

83 Clem. Alex., Protr. I,4,4 (GCS Clemens Alexandrinus I,5,30-33), zitiert nach: Des Clemens von Alexandreia Mahnrede an die Heiden / Der Erzieher Buch 1, aus dem Griech. übers. v. O. Stählin (BKV, 2. Reihe, Bd. 7), München 1934, S. 75. Storch (s. Anm. 82), S. 85. Markschies (s. Anm. 2), S. 242f. In seinem Panegyricus auf das dreißigjährige Regierungsjubiläum Kaiser Konstantins stellt Eusebius nach dem Vorbild des Clemens von Alexandrien ebenfalls die von den Heiden bewunderte Wirkung des Orpheus der mächtigeren Wirkung Jesu gegenüber. Eus., Laud. 14 (GCS Eusebius I,242,17-233,4).

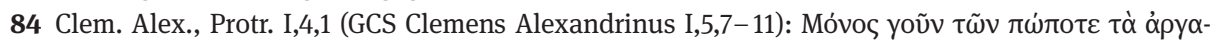

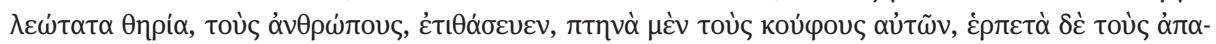

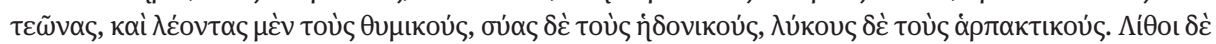

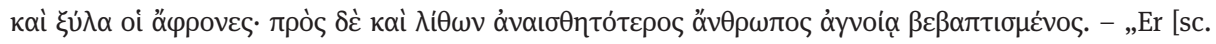
Christus] allein unter allen, die je lebten, zähmte die wildesten Tiere, die Menschen, sowohl Vögel, das sind die Leichtfertigen, als auch kriechende Tiere, das sind die Betrüger, und Löwen, das sind die Jähzornigen, und Schweine, das sind die Wollüstigen, und Wölfe, das sind die Raubgierigen. Stein und Holz aber sind die Unvernünftigen; ja noch gefühlloser als Stein ist ein Mensch, der in Torheit versunken ist.“

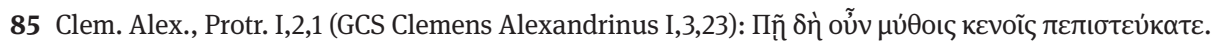
86 Zitat Markschies (s. Anm. 2), S. 246, mit Bezug auf Just., Dial. 69,2 und Apol. I,54,6. 
Wundert es da, dass die dramaturgischen Erzählmuster seines [sc. des Herakles] Mythos und seines Martyriums sich verselbstständigt und auch auf die christliche Passions- und Märtyrerliteratur abgefärbt haben? ${ }^{87}$

In diese Richtung deutet auch, dass die Kirchenväter andererseits gegen eine solche Heroen-Transformation argumentierten und dazu offenbar allen Anlass hatten. ${ }^{88}$ Dass Jesus als Märtyrer die Imitatio des Leidens auch selbstständig begründet, dafür gibt die reiche christliche Märtyrerliteratur ein deutliches Zeugnis ab. ${ }^{89}$ Dennoch, das zeigt der Ausblick auf die narrativen Parallelen in den Martyrien des paganen Heros Hercules und des Christen Polykarp, hat die Märtyrerliteratur sich bei den klassischen Vorbildern bedient und dort ihre literarischen Anleihen genommen.

Der Topos des Heros als Märtyrer und seiner Apotheose findet sich in den paganen Heraklesbildern am stärksten in Senecas Hercules-Tragödien dargestellt. Die Annahme einer direkten Beeinflussung der Evangelisten durch Autoren wie Seneca ist nicht nachweisbar, kategorisch auszuschließen ist sie indessen nicht. Paulus formuliert als erster christlicher Autor das Glaubensbekenntnis vom Auferstandenen. Wenig später entsteht in Rom der Hercules Oetaeus. ${ }^{90}$ Zwierlein weist zu Recht darauf hin, dass der schmerzverachtende Feuertod des Herakles auch im Rom des 2. Jahrhunderts nicht nur bekannt war, sondern als vorbildhaft bewundert wurde. Dies zeigt etwa

[...] das Beispiel des vormals aus Rom ausgewiesenen Kynikers Peregrinus Proteus, der sich im Jahre 165 vor vielen Zuschauern auf einem Scheiterhaufen selbst verbrannte, um gemäß der Lebenshaltung des Hercules die Erhabenheit des Philosophen über Schmerz und Tod zu demonstrieren. Dieses Exemplum erregte damals großes Aufsehen (vgl. Philostr. vit. soph. 2,1,33) und wurde auch von Athenagoras in seiner Schutzrede für die Christen an die Kaiser Marc Aurel und Luc. Verus (legat. pro Christ. c. 26), ferner z.B. von Tertullian (ad martyr c. 4) und später von Ammianus Marcellinus $(29,1,39)$ einer rühmenden Notiz für wert befunden. ${ }^{91}$

\section{Auch Cancik betont die chronologische und örtliche Koinzidenz:}

In den Jahren, als - vielleicht in Rom - die Grundform der Evangelien geschaffen wurde, als Paulus - aus dem durch einen besonderen Herakleskult bekannten Tarsos stammend - in Rom die neue jüdisch-hellenistische Lehre vom Gottessohn und Erlöser verkündete, entstand das Drama vom Herkules auf dem Oeta [.....$^{92}$

87 Hierzu, zum Vorhergehenden und Folgenden siehe Zilling (s. Anm. 40), S. 178 ff. Auch Nesselrath zieht, wie bereits erwähnt, in seiner Analyse des Hercules Oetaeus den naheliegenden Vergleich zwischen der Apotheose des Herakles und der Auferstehung Christi. Vgl. Nesselrath (s. Anm. 68), S. 317. 88 Belege und Verweise bei Zilling (s. Anm. 40), S. 36-39; S. 114-123. Nach der These von Betz zeigt sich dieser Konflikt schon in den Evangelien und der Apostelgeschichte, in denen die beginnende Heroisierung Jesu schließlich unterbunden wird. Vgl. Betz (s. Anm. 16), S. 129.

89 Zilling (s. Anm. 40), S. 204-211.

90 Zwierlein (s. Anm. 68), S. 339 ff. Zwierlein vermutet, dass der Anonymus ein Zeitgenosse Juvenals gewesen sei.

91 Zwierlein (s. Anm. 68), S. $341 \mathrm{f}$.

92 Cancik (s. Anm. 68), S. 258. 
Cancik vertritt aufgrund der von ihm angenommenen zeitlichen Übereinstimmung die Ansicht, dass ein gemeinsamer, allgemein aufgekommener Topos vorausgesetzt werden kann. Des Weiteren verweist er auf das Motiv der Erniedrigung des Erlösers Hercules im Hercules furens. Er sieht darin ein Paradoxon, das den Erlöser schlägt, der zuvor die Erlösung und Befreiung als gewalttätiger Retter vertreten hat. Seine Taten, die Bluttat an der eigenen Familie eingeschlossen, brachten immense Gewalttätigkeiten mit sich. ${ }^{93}$ Die zweite Herculestragödie knüpft hier an und lässt konsequent den heroischen Gewalttäter selbst leiden; diese Tragödie „stürzt den Heros in tiefstes, ganz unheroisches körperliches Leiden“, so Cancik. ${ }^{94}$ Im eigenen erduldeten Leid ist der Heros Gottesknecht und erntet als Lohn die Vergöttlichung und damit die Unsterblichkeit. ${ }^{95}$

Das Konzept der Nachahmung zeigt sich indessen möglicherweise ebenfalls in dem anzunehmenden Selbstverständnis Jesu als leidender Gerechter (Ps 22) und mehr noch als leidender Messias, Gottes- und Menschensohn in der Tradition des leidenden Gottesknechtes (Mk 8,31). Diese Rolle findet sich im sogenannten Deutero-Jesaja (speziell im vierten Gottesknechtslied in Jes 52,13-53,12) in der christlichen Lesart so ausformuliert. Die nachösterliche Christianisierung des jüdischen Vorbildes ist unabhängig vom schwierigen Problem des jesuanischen Selbstverständnisses - naheliegend (vgl. Lk 24,26 und Jes 53,4f.). Zumindest wird sowohl in der judaistischen als auch in der theologischen Forschung davon ausgegangen, dass Jesus als frommer Jude, der in der Tradition seines Volkes unterwiesen war, insbesondere die Prophetie des Jesaja kannte und eventuell auf sich selbst bezogen hat. ${ }^{96}$ Gleichzeitig ist es plausibel, dass die ersten christlichen Gemeinden die Leid- und Todeserfahrung des Messias mit dem Konzept des leidenden Gottesknechtes zusammenbrachten und so besser deuten konnten.

Die Passionsberichte der Evangelisten fallen verglichen mit der Tragödie des Hercules oder der Märtyrerliteratur knapp aus und berichten von einem für den an-

93 Zilling (s. Anm. 40), S. 160.

94 Cancik (s. Anm. 68), S. 257.

95 Zilling (s. Anm. 40), S. 160. Herakles ist sich seiner Apotheose zwar nicht sicher, aber sie ist auf dem Scheiterhaufen auch für ihn zum Greifen nahe und vorhergesagt. Siehe Sen., Herc. O. 1435ff.; vgl. Ov., Met. 9,235ff.; Pind., N. 1,60-70: Teiresias verkündet Herakles’ Apotheose. Vgl. Lk 17,22-37, vom Kommen des Menschensohnes.

96 Einen sehr guten Überblick bietet das Tagungsheft zur debatte der Biblischen Tage vom 25. bis 27. März 2013 der Katholischen Akademie Bayern: Heft 5/2013 mit einschlägigen Beiträgen zu der Thematik u.a. von L. Schwienhorst-Schönberger, Die vier Gottesknechtslieder und die Gestalt des Knechtes JHWHs, S. 21-23; U. Mittmann, Zur neutestamentlichen Rezeption der Gottesknechtslieder am Beispiel des Lukasevangeliums, S. 24-26, die u. a. eine überzeugende synoptische Darstellung von Lk 23,32- 49 und parallel die Bezüge zur Gottesknechtsüberlieferung bei Jesaja herstellt; kritisch dagegen S. Talabardon, „Der Knecht des Ewigen“ - Jescha’ja 52,13-53,12 in jüdischer Interpretation, S. 32-34; Talabardon verweist darauf, dass das Eponym in erster Linie mit Moses in Verbindung gebracht wird (S. 32). Ferner, dass es durch den christlichen Zugriff auf den Titel einen Streit um die Deutungshoheit gibt, der sich auch in der Apologetik findet (S. 34). 
tiken Menschen unfassbaren Ereignis: dass nämlich ein Gottessohn wie ein Schwerverbrecher am Kreuz hängt und so hilflos ist und so gewöhnlich stirbt wie jeder andere Gekreuzigte. Für die paganen Zeitgenossen der Frühchristen war die religiös-kultische Verehrung eines Gekreuzigten nichts anderes als eine Torheit, eine $\mu \omega \rho$ í $\alpha$, in der Wiedergabe bei Justin eine $\mu \alpha v i \alpha$ (Apol. I,13,4), also eine Verrücktheit. ${ }^{97}$

Die Kreuzigung diskreditiert Jesus am stärksten und ist in der antiken Polemik ein Haupteinwand gegen das Christentum. ${ }^{98}$ Wenn Justin nun argumentiert, dass nicht der Kreuzestod, sondern Jesu Taten entscheidend seien, dann liegt der Vergleich mit dem Heros auf der Hand. Justin will den Fokus von der Unmöglichkeit des sterbenden GottMenschen am Kreuz abwenden und auf die Taten lenken. Ein Gott leidet und stirbt nicht, sterblich sind dagegen die „barbarischen Halbgötter und Heroen der Urzeit“. Das Leiden gehört zu ihren Taten..$^{99}$ Entscheidend ist: Helden sind durch ihr Leiden am Ende siegreich. Das Leiden der Heroen ist eben kein Leiden im Todeskampf, sondern es leidet der Held immer im Kontext des Lebens und der ihm gestellten Aufgaben. Christus am Kreuz dagegen ist die elendigste menschliche Kreatur und erst durch die Entwicklung der Auferstehungstheologie bekommt sein Leiden nachträglich einen Sinn für seine Anhänger.

Für die Kirchenväter ist dies das beständigste Vermittlungsproblem. Aufgrund des Einflusses des Heroenkultes, des antiken Totenkultes und den bestehenden

verbreiteten Vorstellungen von der höheren Daseinsform der abgeschiedenen Seelen auf christliche Kreise [...], bei dem immer lebendiger sich bekundenden Bedürfnis, die vermeintliche Lücke zwischen Gott und Welt durch die Statuierung von Mittelwesen auszufüllen, konnte es nicht wohl ausbleiben, dass wenn auch unter anderen Namen und mit vielfach modifizierten Attributen, die christlichen Vollkommenen mit der Zeit in eine Stellung einrückten, ähnlich derjenigen, welche in der gleichzeitigen heidnischen Weltanschauung die Heroen einnahmen, ${ }^{100}$

konstatiert bereits Ernst Lucius 1904 in seiner Untersuchung zu den Anfängen des christlichen Heiligenkultes. So wundert es nicht, dass die frühchristlichen Autoren bei ihren Versuchen, über das Skandalon des Kreuzes zu sprechen und zu predigen, die bekannten Bilder des Mythos transformierten und verwendeten und gleichzeitig um die Verwerfung und Abgrenzung bemüht waren. ${ }^{101}$

97 Aug., Civ.19,23: Toter Gott, gekreuzigter Mensch - mors turpissima crucis (Orig., Comm. in Mt 27,22ff.; Hengel [s. Anm. 41], S. 125, Anm. 1).

98 Just., Apol. I,22,3f.; 13,4; Hengel (s. Anm. 41), S. 129.

99 Hengel (s. Anm. 41), S. 128, siehe Hengels Anm. im Nachtrag auf S. 181. C. M. Bowra, Heldendichtung. Eine vergleichende Phänomenologie der heroischen Poesie aller Völker und Zeiten, Stuttgart 1964, S. 98.

100 E. Lucius, Die Anfänge des Heiligenkultes in der christlichen Kirche, Tübingen 1904, S. 42.

101 Vgl. dazu etwa Lact., Inst. 7 f., der sich dezidiert gegen Hercules wendet und bei seiner Betrachtung der griechischen Götter auf die Darstellung Homers verweist; Just., Apol. I,18, der Odysseus’ Abstieg in die Unterwelt bei Homer als Vergleich und Unterscheidung für den christlichen Glauben an die Unsterblichkeit der Seele heranzieht. In Apol. I,21 argumentiert Justin mit mythologischen Parallelen zur Himmelfahrt Jesu, die z.B. im Vergleich mit den Zeussöhnen und Herakles nichts Befremdliches sei. 


\section{Das Kreuz als Mastbaum - Odysseus und Christus}

Eingängig ist das Bild von der Kirche als rettendes Schiff, wobei „der gewaltige Mastbaum mit der quergestellten Antenne oder Rahe [...] wie von selbst an das Kreuz [erinnert] “. ${ }^{102}$ Automatisch erblickten antike Christen in den Mastbäumen der Schiffe das Kreuz Christi, der durch diese unwillkürliche Assoziation zum unsterblichen Seefahrer wurde. So erklärt Gregor von Nyssa:

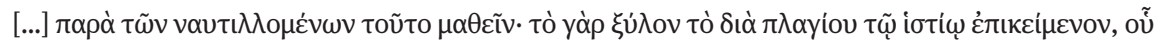

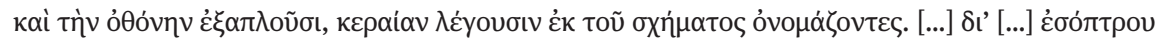

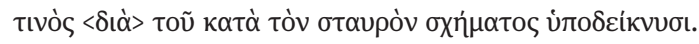

... wie dies auch von den Seeleuten zu lernen ist; denn das Holz, das waagrecht über dem Segel liegt, woran sie auch das Tuch entfalten, heißen sie Querholz [keraia], indem sie es nach seiner Gestalt benennen. Deswegen [...], weil es jenes ist, [...] das seine ihm eigene Kraft, [...] gleichsam wie durch ein Sinnbild und einen Spiegel durch die Gestalt des Kreuzes anzeigt. ${ }^{103}$

Hippolyt führt es folgendermaßen aus:

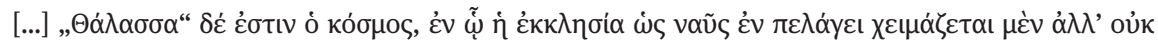

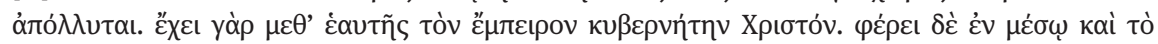

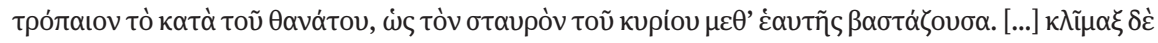

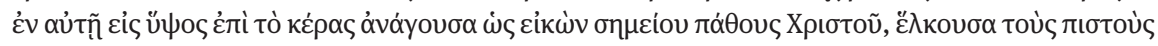

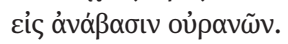

... das Meer ist die Welt, in welcher die Kirche wie ein Schiff auf dem Meere umhergeworfen, aber nicht vernichtet wird, denn sie hat bei sich den erfahrenen Steuermann Christus. In ihrer Mitte führt sie das Banner gegen den Tod, da sie das Kreuz des Herrn mit sich trägt. [...] Die Leiter, welche oben auf den Mastbaum führt, ist die Nachahmung des erlösenden Leidens Christi, welches die Gläubigen zieht, um in den Himmel einzugehen. ${ }^{104}$

Hier erscheint die Kirche als Schiff, welches durch das dämonische Meer der Welt segelt und den Steuermann Christus bei sich hat. ${ }^{105}$ Hippolyt vergleicht in der Refutatio omnium haeresium (= Elenchos = Widerlegung oder Philosophumena) die

Tert., Idol. 20, ereifert sich über Christen, die nach ihrer Bekehrung weiter beim Namen des Hercules schwören. Aug., Civ. 22,10, fordert, die Heiden sollten zugeben, ihre Götter seien wie Hercules nichts weiter als verstorbene Menschen.

102 Hierzu und zum Folgenden siehe Rahner (s. Anm. 1), S. 281-328, Zitat S. 316.

103 Greg. Nyss., In Christi resurrectionem oratio (Gregorii Nysseni opera IX,302,19-303,8). Übersetzung nach: Gregor von Nyssa. Die drei Tage zwischen Tod und Auferstehung unseres Herrn Jesus Christus, eingel., übers. u. komm. v. H. R. Drobner, Leiden 1982, S. 35.

104 Hippol., De Antichristo 59 (GCS Hippolytus I,2,39f.). Übersetzung nach: Hippolytus', des Presbyters und Martyrers, Buch über Christus und den Antichrist, übers. und mit Einl. vers. v. V. Gröne (BKV, 1. Reihe, Bd. 28), Kempten 1872, S. 54f. Vgl. Ambrosius, der das Bild aufgreift in Expl. Psalm. 43,17 (CSEL 64,355,8-16).

105 Rahner (s. Anm. 1), S. 294-300. 
Ansichten gnostischer Häresien mit dem Bild vom aufgepeitschten Meer und expliziert seine Botschaft mit dem Mythos vom Sirenenbesieger Odysseus. Hippolyt zieht nämlich für die Christen den Schluss, sie sollten wie Odysseus ein strategisches Abwehrverhalten gegen die dämonischen Verführungen der Häresien an den Tag legen:

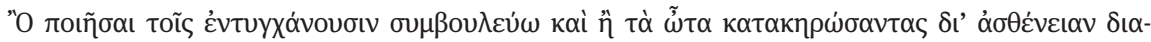

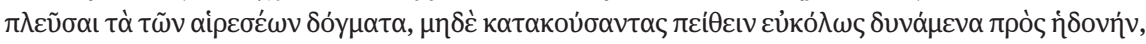

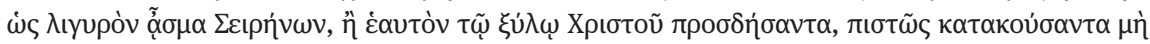

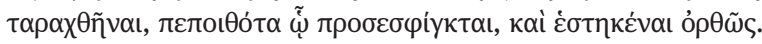

Mein Rat für die, welche sich mit derlei [nämlich den Häresien] beschäftigen, geht dahin, entweder wegen ihrer Schwachheit mit zugeklebten Ohren die Ansichten der Häresien zu durchsegeln und auch nicht auf das zu hören, was, wie der liebliche Gesang der Sirenen, leicht zur Wollust anreizen kann, oder aber sich an das Holz Christi zu binden und in Treuen zu lauschen und sich nicht verwirren zu lassen, sondern aufrecht stehen zu bleiben, im Vertrauen auf das, an das man gebunden ist. ${ }^{106}$

Da der „Normalchrist“ sich wegen seiner Schwachheit in riskantes Fahrwasser begibt, wenn er sich mit häretischen Lehren befasst, sollte dieser sich wie des Odysseus Gefährten Wachs in die Ohren gießen und so den Häresien mit Taubheit begegnen. Dagegen bräuchten die glaubensstarken Christen keine Angst vor den Sirenen zu haben, weil die Fesseln des Glaubens sie aufrecht am „Holz Christi“ halten würden. ${ }^{107}$ Die konkrete Gefahr, die von den Häresien drohe, sei die, dass sie nämlich zur Wollust, also zu sündhafter Unzucht verleiteten. Dazu muss man wissen, dass von den Vätern die grundsätzliche Gefahr der Häresie als Trennung von den „Anordnungen des Bi-

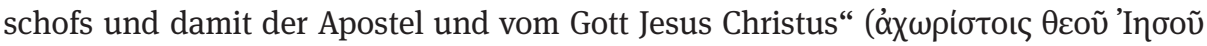

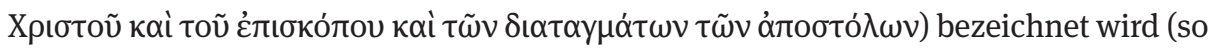
drückt es Ignatius in seinem Brief an die Trallianer aus [7,1-2]). Ignatius nennt mithin die Voraussetzungen dafür, kein Häretiker zu werden. Das bedeutet im Umkehrschluss, wer die Häresien hört, setzt seine christliche Existenz und damit sein individuelles Heil aufs Spiel. Mit anderen Worten, es geht nicht nur um eine Auseinandersetzung um Leben und Tod, sondern um das ewige Leben - eine Verheißung, die wir eben auch von den Sireneninseln kennen.

Odysseus bewährt sich am Mastbaum nicht durch ein Wunder, sondern durch einen Trick, der zwar auf göttliche Weisung, aber doch in der Ausführung einer menschlichen List gleichkommt. Erniedrigung und Fesselung des Odysseus sind freiwillig oder besser gesagt, sie entspringen der Ratio des klugen Odysseus, den Bogen nicht zu überspannen. Ihm ist klar, dass er, wenn er sich noch weiter vorwagt, sein Leben verlieren wird. In Odysseus verbindet sich intellektuelle Einsichtsfähigkeit mit

106 Hippol., Ref. omn. haer. 7,13,3.

107 Ebenso Clem. Alex., Protr. XII,118,1-4 (GCS Clemens Alexandrinus I,83,8-30). Vgl. dazu Markschies (s. Anm. 2), S. $236 \mathrm{f}$. 
dem glücklichen Umstand, in besonderer Weise ein Günstling weiblicher Gottheiten zu sein, die ihm lebensrettende Anweisungen vermitteln, ohne die er das Sirenenabenteuer sicherlich nicht bestanden hätte.

Wie steht es aber mit Christus am Kreuz? Von außen betrachtet ist er ein Anticharismatiker und ein Versager. Die Bewährung scheitert, er bewirkt an sich selber kein Wunder. Das ist nur auf den ersten Blick ein Paradoxon, oder vielmehr eine Verkennung, denn es geht ja gerade darum, in der Sprache der Evangelien, den Kelch des Leidens auszutrinken. Christus steigt also nicht vom Kreuz herab, sondern am Kreuz schwindet seine charismatische Autorität, die er sich vor allem als Wundertäter aufgebaut hat. Er schreit sogar verzweifelt: „Mein Gott, mein Gott, warum hast du mich verlassen?“, wodurch er sein Scheitern sogar offen ausspricht. Im Kern liegt die „revolutionäre Macht“ des Gekreuzigten darin, dass mit Christus ein Mensch stirbt und dann aber aufersteht. Wenn das so ist, dann besteht zumindest für die Menschen nach christlicher Auffassung die prinzipielle Hoffnung, es ihm gleichzutun. Erst die nachträgliche christliche Interpretation, dass gerade der stellvertretende Sühnetod des Heilands für die Menschheit notwendig war, macht den heroischen Sinn dieses Sterbens aus. Das Kreuz wird so zum zentralen Siegessymbol umgedeutet.

Jedoch bedarf dieser Zusammenhang einer erfolgreichen Vermittlung. Hier greifen die Kirchenväter, wie wir an einem frühen Vertreter gesehen haben, auf die Möglichkeiten einer christlichen Homerinterpretation zurück. Diese leistet jedoch noch mehr als die Kommunikation des Kreuzes als Siegeszeichen. Die vorhin besprochene Hippolytstelle zeigt ganz deutlich, wie zudem die Rechtgläubigkeit gegen Häresien argumentativ bewältigt wurde. Dazu (etwas pathetisch) Carl Schneider: „Der Mast, an den Odysseus sich binden lässt, ist das Kreuz, das vor den Sirenen der Sünde und der Welt errettet." ${ }^{108}$ Erstaunlich bleibt indessen der Umstand, dass in dieser Auseinandersetzung Christus mit Odysseus verbunden und auf die topische Kontinuität des an den Mastbaum gefesselten Odysseus als Strategie zur Häretikerabwehr abgehoben wird.

Da das Bild des Odysseus z. B. durch die weit verbreitete Keramik so vertraut und deutlich ist, wird es in dem beschriebenen antihäretischen Kontext verwendet und untermauert etwa die Katechese, auch der Herr habe in der Wüste und vor allem in Getsemani einer teuflischen Versuchung widerstanden. Darum wird Christus bei Hippolyt als Odysseus oder Kapitän dargestellt. Auf diese Weise wird nun allerdings auch Odysseus heilig. Das Bild des Odysseus am Mastbaum erlebt durch die christliche Verwendung Kontinuität und erfährt dabei eine nachdrückliche Christianisierung und Transformation. D.h. in der christlichen Deutung erfolgt die Vereinnahmung des paganen Bildes, dann nämlich, wenn Christus als Kapitän oder eben als Odysseus der Kirche erscheint. Ein Problem bleibt jedoch bestehen: Odysseus leidet nicht stellvertretend für die Gefährten, sondern er leidet in eigener Sache oder an seiner Hybris. Christus dagegen stirbt den Sühnetod und rettet die Menschheit, insofern ist die

108 Schneider (s. Anm. 5), Bd. 1, S. 320. 
Bildkorrespondenz oder die Analogie verzerrt. Die Heilsbedeutung des Todes Jesu ist in der Tat originell. Die jüdische Tradition des leidenden Gottesknechtes kennt die Vorstellung, dass dieser „um unserer Sünde willen durchbohrt und zerschlagen wird“ (Jes 53,5). Neu ist indessen die Heilsbedeutung des elenden Martertodes am Kreuz.

Doch weil man sich des Skandalons bewusst war, suchten die Kirchenväter einerseits nach Vermittlungsmöglichkeiten und griffen dabei auf die altbekannten Mythen und Figuren zurück, andererseits waren sie gezwungen, die Christologie von solchen paganen Heroen- und Göttervorstellungen zu unterscheiden. In der Dogmatik der Kirchenväter wurde die Anstößigkeit des Kreuzes in eine heilstheologische Notwendigkeit umgedeutet: Nur durch das Kreuz sollte die Sündenvergebung gewährleistet und die Auferstehung „im Hafen des Heils“ möglich sein. Damit bot sich für die Kirchenväter an, auf das bekannte Bild von Odysseus am Mastbaum zurückzugreifen. Es geht diesen dabei nicht um den berühmten Helden des paganen Mythos, sondern darum, Heilswege durch das Mittel der Allegorie deutlich zu machen.

Die Analyse der Verhältnisse im Rom zur Zeit des Hippolyt weist außerdem auf das Ringen der Gemeinden hin, der gnostischen Infiltrierung etwas entgegenzusetzen und im Machtkampf gegen den Bischof Kallist zu bestehen. Damit wird das Bild des mythologischen Helden zudem ein Instrument innerchristlicher Auseinandersetzungen. ${ }^{109}$

\section{Schluss}

Um einen Bogen zurück zu Auerbach zu schlagen - dieser ist der Ansicht, ${ }^{110}$ dass der Ort des Geschehens, das Milieu und überhaupt die Jesus-Figur selbst mit dem erhabenen Stil der klassisch-antiken Literatur völlig unvereinbar gewesen seien. Die figurale Deutung erkennt Auerbach insbesondere als spezielles Merkmal der christlichen Tradition. Meines Erachtens zeigen jedoch neben den alttestamentlichen die mythologischen Beispiele, dass die christliche Interpretation der Geschichte Jesu und die Figuration der Erlösergestalt Vorstellungen, Verweise und Erzählmuster aufgreifen, die von den Kontexten der paganen Umwelt ebenso wenig zu trennen sind wie von ihren jüdischen Vorbildern. So hat schon Joseph Campbell in seiner umfassenden Betrachtung der immer wiederkehrenden Topoi des Helden gezeigt, dass letztendlich keine mythische oder religiöse Erzählung von den archetypischen Abläufen des Monomythos zu trennen ist, weder Jesus noch Buddha, weder die griechischen noch die

109 Vgl. dazu auch Oehl (s. Anm. 2), S. 338: „Man knüpfte an die bereits vorchristliche Praxis an, den Mythos in die Polemik einzubeziehen, entwickelte übernommene Bilder aber eigenständig weiter und passte sie an die Bedürfnisse der eigenen Polemik an.“

110 Auerbach stützt sich hierin auf Norden, vgl. Auerbach (s. Anm. 6), S. 45-49. 
römischen Götter und Heroen. ${ }^{111}$ Selbst das leere Grab, so ungewöhnlich es auch erscheint, ist nicht ohne Parallele. ${ }^{112}$

Ich wage zum Schluss meiner Ausführungen die These, dass die Märtyrerliteratur sich stärker als die Evangelien von der klassischen Literatur beeinflussen lässt verwiesen sei in diesem Zusammenhang nur kursorisch auf Assmanns erinnerungsgeschichtlichen Ansatz. ${ }^{113}$ Neben dem Umstand, dass intellektuelle Christen als ehemalige Heiden durchaus umfassend gebildet waren, ${ }^{114}$ hat das gemeinsame kulturelle Gedächtnis sicherlich eine Rolle gespielt.

Auerbach ist indes zuzustimmen, wenn er ausführt, dass die Evangelien und die Apostelgeschichte erstmals „die Entstehung einer geistigen Bewegung in der Tiefe des alltäglichen Volkes, mitten aus dem zeitgenössischen alltäglichen Geschehen heraus“ dargestellt haben und dass dieses „für die Verfasser der neutestamentlichen Schriften revolutionäres Weltgeschehen“ gewesen sei. ${ }^{115}$ Diese haben neue historische Ordnungsbegriffe gefunden (Auerbach listet hierzu Begriffe wie Zeit des „Gesetzes“, der „Sünde“, der „Gnade“, der „Gerechtigkeit“, der „Liebe“, der „Kraft“ und des „Geistes“ auf). ${ }^{116}$ Zudem dürfe man nicht vergessen, dass die bar jeder Wissenschaftlichkeit und Objektivität erzählte Heilsgeschichte „[...] aus der Geschichte heraus, in die Endzeit [...] führt, also nach oben, [...] und dass überhaupt die bei den antiken Betrachtern ruhenden Tiefenschichten in Bewegung gerieten“. ${ }^{117}$

Mit der beginnenden Heidenmission verwandelten sich endgültig eine Reihe von alttestamentlichen Figuren zu Vorverkündern Jesu, erhalten sinnliche Erscheinungen eine religiöse Bedeutung, verweist wie gesagt Adams Schlaf auf Christi Todesschlaf, zeigt Adams Seitenwunde und die daraus entnommene Rippe, das Weib Eva, die Mutter-Kirche sowie Blut und Wasser der Seitenwunde Christi die Sakramentssymbole.

In seinem Mimesis-Kapitel zu Adam und Eva (Kap. VII) führt Auerbach dazu ein volkstümliches französisches Weihnachtsspiel aus dem 12. Jahrhundert an: Jedes Geschehen sei dort in seiner alltäglichen Wirklichkeit zugleich von welthistorischer Relevanz. Bemerkenswert sei es, dass zunächst Gott selbst Figura genannt würde, was sich zunächst auf den Darsteller, den Geistlichen, der Gott zu figurieren hatte, bezöge

111 J. Campbell, Der Heros in tausend Gestalten, Frankfurt a. M. 1999, vgl. etwa S. 42 ff.; S. 247 ff. 112 Wie ungewöhnlich das leere Grab ist, zeigt sich nicht zuletzt am anhaltenden Ringen um die Auslegung in der Forschung. Vgl. dazu etwa Thiessen (s. Anm. 46), S. 55-78, mit Hinweisen auf die wichtigsten Positionen und Argumentationen. Theologisch bedeutet die Auferstehung im christlichjüdischen Verständnis die Annahme eines Opfers und damit die Vollendung des Sühnetodes Jesu aus christlicher Perspektive.

113 J. Assmann, Das kulturelle Gedächtnis. Schrift, Erinnerung und politische Identität in frühen Hochkulturen, 5. Aufl., München 2005, S. 48-56; ders., Die mosaische Unterscheidung oder der Preis des Monotheismus, München/Wien 2003, S. $89 \mathrm{ff}$.

114 So etwa K. Pietzner, Ungebildete Konkurrenten? Die Auseinandersetzung zwischen Christen und Heiden in vorkonstantinischer Zeit (Studien und Texte zu Antike und Christentum), Tübingen 2011.

115 Auerbach (s. Anm. 6), S. 46.

116 Auerbach (s. Anm. 6), S. 48.

117 Auerbach (s. Anm. 6), S. 48. 
und den man sich scheute „Gott“ zu nennen, so wie die anderen Darsteller, etwa von Adam und Eva, mit den Namen ihrer Rollen angesprochen wurden. Man könne es aber auch so erklären, meint Auerbach weiter, dass in der Gottesgestalt „schon der erlösende Heiland figural gegenwärtig“ sei. ${ }^{118}$

Darauf beziehe ich mich, wenn ich meine, dass im antiken Heros - ob nun in der Literatur oder in der bildenden Kunst oder auf Alltagsgegenständen - eine Figur angelegt oder ein Typus figuriert ist, welcher von nachhaltigem Einfluss auf die Autoren des Neuen Testaments, der Märtyrerliteratur aber auch auf Künstler, Kunst- und Kulturgeschichte geblieben ist.

118 Auerbach (s. Anm. 6), S. 151. 